\title{
Global Trends of Sea Surface Gravity Wave, Wind, and Coastal Wave Setup
}

\author{
YUCHUN LIN \\ National Central University, Taoyuan City, Taiwan \\ LEO OEY \\ National Central University, Taoyuan City, Taiwan, and Princeton University, Princeton, New Jersey
}

(Manuscript received 14 May 2019, in final form 4 September 2019)

\begin{abstract}
Assessing trends of sea surface wave, wind, and coastal wave setup is of considerable scientific and practical importance in view of recent and projected long-term sea level rise due to global warming. Here we analyze global significant wave height (SWH) and wind data from 1993 to 2015 and a wave model to (i) calculate wave age and explain the causal, or the lack thereof, relationship between wave and wind trends; and (ii) estimate trends of coastal wave setup and its contributions to secular trends of relative sea level at coastal locations around the world. We show in-phase, increasing SWH and wind trends in regions dominated by younger waves, and decreasing SWH trends where older waves dominate and are unrelated to the local wind trends. In the central North Pacific where wave age is transitional, in-phase decreasing wave and wind trends are found over the west-northwestern region, but wave and wind trends are insignificantly correlated in the southsoutheastern region; here, a reversed, upward momentum flux from wave to wind is postulated. We show that coastal wave setup depends primarily on open-ocean SWH but only weakly on wind, varying approximately like $\mathrm{SWH} /(\text { wind speed })^{1 / 5}$. The wave-setup trends are shown to be increasing along many coastlines where the local relative sea level trends are also increasing: the North and Irish Seas, Mediterranean Sea, East and South Asian seas, and eastern United States, exacerbating the potential for increased floods along these populated coastlines.
\end{abstract}

\section{Introduction}

A substantial portion ( $~ 90 \%)$ of wind energy input into the global ocean generates surface gravity waves (hereafter, waves) (Lueck and Reid 1984; Wunsch and Ferrari 2004). When locally dissipated, mostly as young wind seas, that is, waves under the influence of local wind, waves produce and modulate mixing in oceanic surface layer, modifying the surface fluxes (Andreas and Emanuel 2001; Mellor and Blumberg 2004). The exchange of momentum, mass, and heat across the airsea interface influences global and regional weather and climate (Trenberth et al. 2007; Oey et al. 2013; Li et al. 2017), small-scale winds (Wallace et al. 1989; Chelton et al. 2004; Oey et al. 2015), storm tracks (Nakamura et al. 2004; Huang and Oey 2019a), cyclone intensification (Zhang and Oey 2019a), ecosystem and fisheries (Oey et al. 2014, 2018), and others. Openocean waves can traverse long distances as swells, that

\footnotetext{
Corresponding author: Leo Oey, lyo@alumni.princeton.edu
}

is, surface waves that outrun their generating wind. In the open ocean, swells can transfer momentum upward into the marine boundary layer (Harris 1966; Grachev and Fairall 2001; Ardhuin et al. 2009). When dissipated across shallow seas near the ocean's continental perimeter (Komen et al. 1994; Wunsch and Ferrari 2004), waves contribute in altering the local morphology (Hyndman and Hyndman 2010); influencing the regional ecosystem (Rogers et al. 2016); creating hazardous conditions for ships, civilians, and infrastructures (Salamon et al. 2017); breaking up ice shelf and accelerating sea ice loss (Massom et al. 2018); and others. Knowledge of ocean surface waves is thus essential in many applications and in improving our understanding of the climate system and interaction between various components of the planetary ecosphere (Möller 2010).

In conjunction with global warming and sea level rise, there is interest in using observations to examine longterm (longer than, say, two or more decades) changes of wind and wave in the global ocean, and their influence near the coast. Gulev and Hasse (1999) used ship data 
and found an increase in the significant wave height [SWH; $=H_{s}=4 E^{1 / 2}$, where $E$ is the total energy of the wave field (Longuet-Higgins 1952)] from 1964 to 1993 over most of the North Atlantic Ocean except the western and central subtropics. Kushnir et al. (1997) showed that the increased SWH may be related to the positive phase of the North Atlantic Oscillation (see also Cox and Swail 2001; Fan et al. 2012). Allan and Komar (2000) used buoy data along the U.S. West Coast and found that wave trends there are significantly affected by shifts in storm tracks caused by the changing phase of El Niño-Southern Oscillation. Young et al. (2011) analyzed trends of global ocean wind speed and wave height from 1991 to 2008 and 1985 to 2008, respectively, on a $2^{\circ} \times 2^{\circ}$ grid. They found generally increasing trends of wind speed (the "10-m wind") but less significant trends in the SWH. In the Southern Ocean, there appears to be a causal relationship between increasing trends of wind speed and wave height. The relationship in the Northern Hemisphere is unclear; the authors pointed out the difficulty of distinguishing locally generated wind seas and remotely generated swells. Young and Ribal (2019) extended the wind and wave trend analyses using a longer dataset, from 1985 to 2018, on the same $2^{\circ} \times 2^{\circ}$ grid. They found significantly negative SWH trend in the North Pacific that is inconsistent with the unclear (slightly positive) wind speed trend. There are also significant differences between the two studies in the wind speed trends over the western equatorial $\mathrm{Pa}$ cific. Here, significantly negative wind speed trend extends into the Maritime Continent and the eastern Indian Ocean in Young and Ribal (2019), consistent with Huang and Oey (2019b); however, the wind speed trend is slightly positive and insignificant in Young et al. (2011).

This study examines trends of global wind, wave and coastal wave setup from 1993 to 2015 . The first goal is to use (near-)global $1^{\circ} \times 1^{\circ}$ wave and $14^{\circ} \times 1 / 4^{\circ}$ wind resolution, and a common time period for both variables to compute the corresponding trends and then, by also estimating the wave age, to more completely explain and discover new things about the spatially variable wind and wave trends in different parts of the global ocean. The resolutions we use are higher than the $2^{\circ} \times 2^{\circ}$ global data used in Young et al. (2011) and Young and Ribal (2019), and allow improved representations of wind and wave in marginal and coastal seas. The second goal of our study is to use the above data to assess how longterm trends of open-ocean wind and wave affect nearcoast wave "setup" (Longuet-Higgins and Stewart 1964), and how the latter in turn may modify the secular trends of relative sea level at tide gauge stations around the globe. Accelerated global sea level rise is observed in recent decades and is projected for the next century (Trenberth et al. 2007; Hay et al. 2015). Knowledge of how wave setup near the coast may be modulated by changes in open-ocean wind and wave climate is of societal interest. Along populated coastlines where increasing trends of (relative) sea level are strong, for example, the U.S. East Coast (Mulkern 2017; Piecuch et al. 2018), South Asia, and others (see below), a concurrent rising trend in wave setup can potentially pose more dire consequences to coastal residents and infrastructures, especially in the event of high tides and intense storms (Oey and Chou 2016).

The remainder of the paper is organized as follows. Section 2 describes the data and method used. We present the results in section 3 , and summary and discussion in section 4 .

\section{Data and method}

\section{a. SWH}

We use the near-global $\left(80^{\circ} \mathrm{S}\right.$ to $\left.80^{\circ} \mathrm{N}\right)$ along-track satellite SWH data (from ftp://ftp.ifremer.fr/ifremer/ cersat/products/swath/altimeters/waves/) for the period 1 January 1993 to 31 December 2015 to estimate SWH trends. The data are monthly in order that sufficient number of satellite track data can be collected and averaged onto $1^{\circ} \times 1^{\circ}$ near-global grid. Grids with missing data were filled using a two-dimensional Gaussian filter; they represent about $1.2 \%$ of the total data. Neither smoothing nor interpolation was applied. Other details including validation against buoy data are given in Lin et al. (2019), and are not repeated here. $^{1}$

\section{b. Surface $(10 \mathrm{~m})$ wind speed and wind power}

The Cross-Calibrated Multi-Platform, version 2 (CCMPV2; http://www.remss.com/measurements/ccmp) (Atlas et al. 2009; Wentz et al. 2016), wind at $1 / 4^{\circ} \times 1 / 4^{\circ}$ spatial resolution and 6-h temporal resolution from $78.375^{\circ} \mathrm{S}$ to $78.375^{\circ} \mathrm{N}$ and from July 1987 to present are available, although we only use the data from 1 January 1993 to 31 December 2015 to coincide with the SWH data. The CCMPV2 wind underestimates strong winds and was therefore corrected by incorporating cyclone winds. Detailed descriptions are given in Zhang and Oey $(2019 a, b)$, and are therefore not repeated here;

\footnotetext{
${ }^{1}$ In Lin et al. (2019), we misstated that the SWH data were monthly averaged instead of simply monthly and that the Gaussian filter could smooth the data instead of being used to simply fill the missing grids.
} 
the cyclone-corrected data are referred to as CCMPV2-C and are freely available (see link in acknowledgments).

The frequency-integrated rate of wind energy input into surface waves is proportional to wind power (minus dissipation) (Hwang and Sletten 2008; Mellor et al. 2008; Donelan et al. 2012; Hwang and Walsh 2016). In addition to wind speed, we also use wind power to examine the potential connection between wind and wave (Lin et al. 2019). The wind power is estimated as $\rho_{a} C_{d} V^{3}$, where $\rho_{a}=1.23 \mathrm{~kg} \mathrm{~m}^{-3}$ is the air density, $V$ is the $10-\mathrm{m}$ wind speed in $\mathrm{m} \mathrm{s}^{-1}$, and $C_{d}$ is the wind speeddependent drag coefficient based on a formula (see Oey et al. 2006, 2007) that imposes the high wind speed limit of Powell et al. (2003). Wind speed and power were calculated using the 6-hourly data and then daily averaged to calculate trends.

As a check, we compare the wind speed trend calculated using the present data with Young et al. (2011), for the same period from 1991 to 2008. In comparing our calculated trend with theirs, wind speed is the only variable with the common period that can be compared. The result is shown in Fig. A1 (top), which we compare with Young et al.'s Fig. 1 (top). There is general agreement between the two trends, which show mostly positive trends with pockets of negative trends. However, because the present data have higher spatial $\left(1 / 4^{\circ} \times 1 / 4^{\circ}\right.$ vs $2^{\circ} \times 2^{\circ}$ ) and temporal (daily vs monthly) resolutions, Fig. A1 shows much more distinct areas of statistically significant trends, of both signs, as well as clearer trends in coastal regions that are better resolved. For example, across the central North Pacific $150^{\circ} \mathrm{E}-150^{\circ} \mathrm{W}$ and $30^{\circ}-$ $55^{\circ} \mathrm{N}$, Fig. A1 shows significant negative wind speed trend compared with insignificant, weak negative trend in Young et al. As a further check, Fig. A1 also shows trends calculated using two other daily datasets: ECMWF (middle) and NCEP (bottom). The above negative trend over the central North Pacific also appears in both data. However, over the global ocean, both ECMWF and NCEP wind speed trends show more negative values than Young et al. and our data.

\section{c. The inverse wave age}

We estimate the inverse wave age, $\omega_{n}$, derived in Zhang and Oey (2019a) using the Hwang and Walsh (2016) wind-wave triplets formulation for the peak phase speed $C_{p}$ :

$$
w_{n}=V / C_{p}, \quad C_{p}=9.2918 H_{s}^{0.5848} / V^{0.1696}\left(\mathrm{~m} \mathrm{~s}^{-1}\right),
$$

where the constant 9.2918 involves the Earth gravity $g$ and has a dimension of $\left(\mathrm{m} \mathrm{s}^{-2}\right)^{0.5848}$. The derivation of $C_{p}$ made use of a wave-growth function, and the formula is strictly consistent only with younger waves, that is, wind seas, for which $\omega_{n}$ is near one or larger. On the other hand, we found that when using the observed $H_{s}$ from satellite altimetry, the spatial pattern of $\omega_{n}$ obtained from (1) compares well with the $\omega_{n}$-pattern calculated directly using the peak phase speed $C_{p \text { Model }}$ from a 23-yr (1993-2015) WAVEWATCH III model output (Lin et al. 2019) in the Pacific (Fig. A2); the corresponding regression $r^{2}=0.74$ and slope $=1.13$. The good agreement is perhaps fortuitous but allows an empirical delineation of potential regions of dominance of wind seas or/and swells.

\section{d. Relative sea level ( $\left.\eta_{\mathrm{RSL}}\right)$ and absolute sea level $\left(\eta_{\mathrm{ASL}}\right)$}

Relative sea level (RSL) is defined as the distance between Earth's crust and sea surface, that is, it is referenced to the local solid surface of Earth. In contrast to satellite altimeter, which measures absolute sea level $\left(\eta_{\text {ASL }}\right)$ referenced to Earth's center of mass and is available for a relatively short time since the 1990s (Mitrovica et al. 2001; Nerem and Mitchum 2001; Clark et al. 2002; Douglas and Peltier 2002), RSL is recorded by coastal (or island) tide gauges, many dating back to the 1860-1930s. Secular trend of relative sea level, $d \eta_{\mathrm{RSL}} / d t$, is therefore the algebraic sum of changes in vertical movement of the Earth crust, $d h_{\mathrm{EC}} / d t$ (positive upward), and absolute sea level $d \eta_{\mathrm{ASL}} / d t$ (Farrell and Clark 1976; Milne et al. 2001):

$$
d \eta_{\mathrm{RSL}} / d t=-d h_{\mathrm{EC}} / d t+d \eta_{\mathrm{ASL}} / d t+\varepsilon,
$$

where $\varepsilon$ includes effects of geoid and rotational feedback (e.g., Milne and Mitrovica 1998; Mound and Mitrovica 1998; Mitrovica et al. 2001; Tamisiea et al. 2001; Peltier 2004). For $d \eta_{\mathrm{ASL}} / d t$, in addition to a global long-term rise due to, for example, seawater expansion and addition of ocean water mass by land-ice and glacier melting because of ocean warming, it can be generalized to locally also include changes caused by ocean dynamics at interannual and interdecadal time scales (Merrifield and Maltrud 2011; Goddard et al. 2015; Swapna et al. 2017; Domingues et al. 2018; Volkov et al. 2019). We use absolute sea level data (from https://www.aviso.altimetry.fr/en/data.html) and relative sea level from tide gauge data provided by the National Oceanic and Atmospheric Administration (https://tidesandcurrents.noaa.gov/sltrends/sltrends.html) and the Permanent Service for Mean Sea Level (https:// www.psmsl.org/) at coastal stations around the globe. The tide gauge data were monthly averaged to remove highfrequency fluctuations and, due to their long records, the trends approximate long-term changes in "still water level," in which variation due to waves and ocean dynamics are filtered. 


\section{e. Wave setup $\left(\eta_{\mathrm{ws}}\right)$}

Surface gravity waves produce "wave setup" when open-ocean waves run up a sloping beach and break (Longuet-Higgins and Stewart 1964). The loss of wave energy leads to an onshore decrease in the wave radiation stress $S_{x x}$, that is, $d S_{x x} / d x<0$ (where $x$ is directed normal to the shoreline, positive onshore), which, in order to balance the excess momentum flux, requires an onshore increase in sea level, that is, wave setup $\left(\eta_{\mathrm{ws}}\right)$ : $d \eta_{\text {ws }} / d x=-(\rho g h)^{-1} d S_{x x} / d x, h=$ water depth and $\rho=$ seawater density. We relate the wave setup near shore to open-ocean significant wave height $H_{s}$ from satellite and peak wavelength $\lambda_{\text {po }}$ using the empirical formula of Stockdon et al. (2006):

$$
\eta_{\mathrm{ws}}=0.385 \beta\left(\lambda_{\mathrm{po}} H_{\mathrm{so}}\right)^{1 / 2},
$$

where $\beta$ is the beach slope, which is taken to be a constant, $=0.05$; the same formula was used by Ruggiero (2013), Serafin et al. (2017) and Melet et al. (2018). The $\lambda_{\text {po }}$ is related to the peak phase speed $C_{\text {po }}$ using the deep-water dispersion relation:

$$
\lambda_{\mathrm{po}}=2 \pi C_{\mathrm{po}}^{2} / g .
$$

This equation is used over deep water only using satellite data, for open-ocean waves/swells that propagate to the edge of the continental shelf where the water depth exceeds $200 \sim 500 \mathrm{~m}$, say.

In (4), we may approximate $C_{\mathrm{po}} \approx C_{p(1)}$ obtained from formula (1), which, however, is strictly valid only for wind seas. To correct for swells, we regress the inverse wave age $\omega_{n \mathrm{ww}}$ calculated directly from a 23-yr (1993-2015) WAVEWATCH III (WW3) model that included both wind seas and swells and that yielded results in good agreements with buoy and satellite observations (Lin et al. 2019), against the $\omega_{n(1)}\left(H_{s \mathrm{Ww}} ; V\right)$ obtained from (1) using the model $H_{s}$ ww3. The result is

$$
\begin{aligned}
\omega_{n \mathrm{WW} 3}= & 0.782 \omega_{n(1)}\left(H_{s \mathrm{WW} 3} ; V\right) \\
& +0.084\left(r^{2}=0.67, p<10^{-3}\right) .
\end{aligned}
$$

In most region, the inverse wave age $\omega_{n} \gtrsim 0.385$ (Fig. A2 lower-left panel), and (5) then gives $\omega_{n \mathrm{ww} 3}<\omega_{n(1)}$, as it should to correct for swell effects. We assume that this model-derived statistical relation (5) between the true $\omega_{n}$, that is, the left side, and the approximate $\omega_{n}$ from formula (1), that is, the right side, is valid also for observations. The closeness of modeled and observed $\omega_{n}$, noted previously in Fig. A2, justifies the assumption. Thus,

$$
C_{\mathrm{po}}=V /\left(0.782 V / C_{p(1)}+0.084\right),
$$

where the $C_{p(1)}$ is calculated from (1) using the observed $H_{s}$ from satellite. Substituting (6) into (4) gives $\lambda_{\mathrm{po}}$, and the $\eta_{\mathrm{ws}}$ is then calculated from (3). In general, the correction is only significant at stations near the eastern boundary of the ocean basin; otherwise, $C_{\mathrm{po}} \approx C_{p(1)}$ using (1) provides a good approximation.

The use of (3) for wave setup is not without controversy—see, for example, Aucan et al. (2019) and Melet et al. (2019). Nonetheless, the formula provides a simple estimate. Substituting the above numbers, using (1) and (4) for $\lambda_{\text {po }}$, and noting that the wind speed dependency in (1) is weak, we obtain $\eta_{\mathrm{ws}} \approx 0.17 H_{s}$, which agrees with the formula used by Vousdoukas et al. $(2017,2018)$ : $\eta_{\mathrm{ws}}=0.2 H_{s}$. The use of (3) in the present study may therefore be regarded as providing a conservative, low estimate of the wave setup.

\section{f. Trends, regressions, and significance}

Linear trends and regressions are used in all the analyses (Bendat and Piersol 1986; Press et al. 1992). They are considered significant only if the corresponding $p$ value $\leq 0.05$ (i.e., $95 \%$ confidence level). Least squares regression can be sensitive to outliers. We therefore also rechecked the trends as the "Sen slopes" using the Theil-Sen estimator (Theil 1950a,b,c; Sen 1968), used also by Young et al. (2011) and Young and Ribal (2019). Applied to our data, the two methods give virtually identical results.

\section{Results}

\section{a. Seasonal climatology}

Seasonal variability of wave and wind were previously examined by Young (1999) for the period 1990-99. We reexamine seasonal variability here using our data, as a prelude to presenting long-term trends, to assess potential regions of dominance of wind seas or/and swells. Figure 1 shows seasonal maps of SWH (shading) and wind (vectors). The months of highest SWH are during the winter season in both hemispheres. The SWH and wind are larger at higher latitudes in the winter seasons, exceeding $5 \mathrm{~m}$ and $10 \mathrm{~m} \mathrm{~s}^{-1}$, respectively, in both the Southern Ocean and subpolar North Pacific and Atlantic Oceans. Higher SWH in northern Pacific and Atlantic Oceans are related to boreal winter's cyclonic low pressure systems that generate strong westerly winds (Fig. 1a). In austral winter (Fig. 1c), largest SWH and wind appear in the Indian Ocean sector of the Southern Ocean due to the strong westerly wind jet. Figure 1c also shows high SWH in the Arabian Sea, 

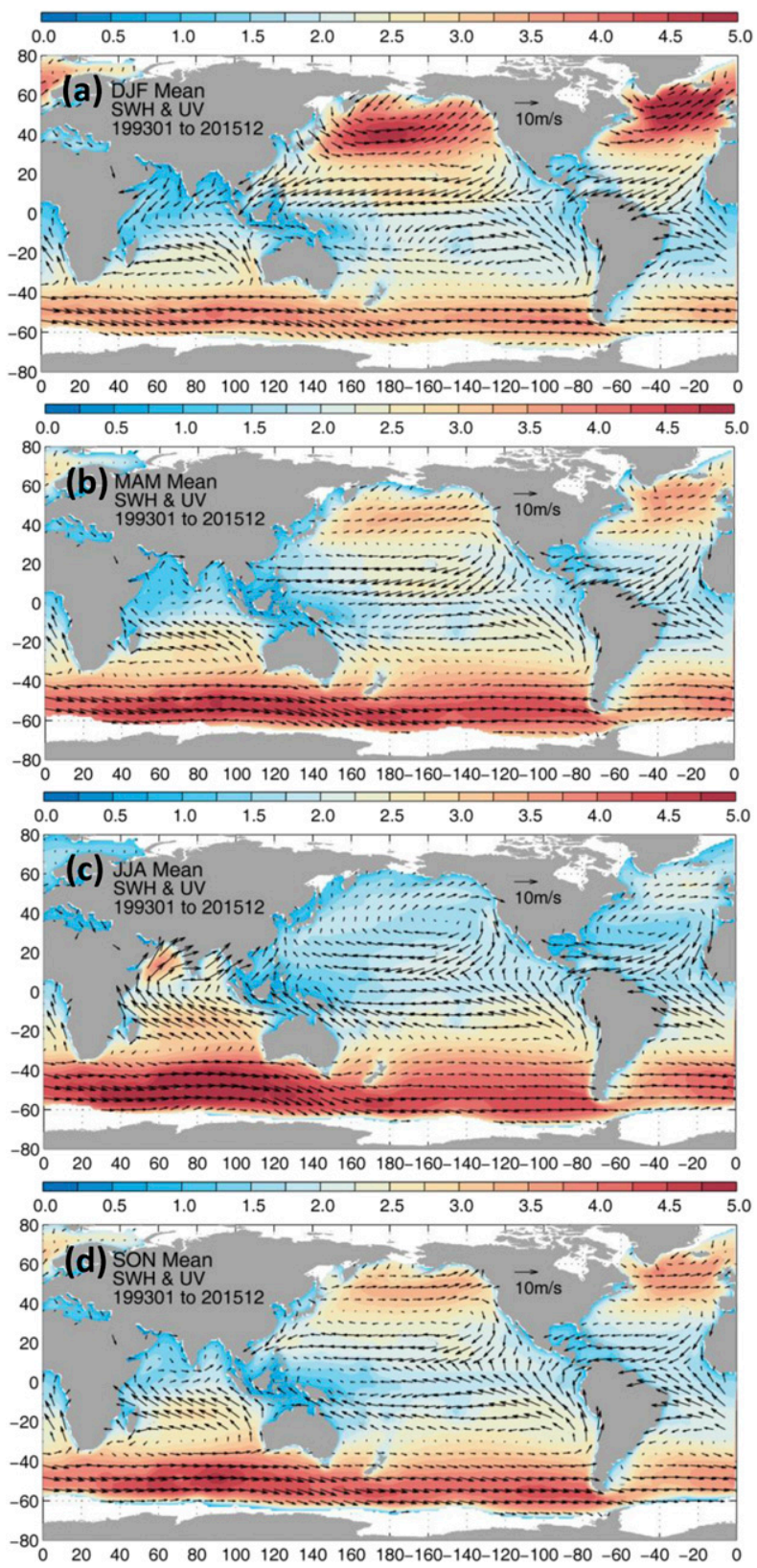

FIG. 1. Climatological SWH (color shading) and wind velocity (vectors) in (a) DJF, (b) MAM, (c) JJA, and (d) SON from January 1993 to December 2015. The SWH data are based on satellite altimetry and the wind is from the CCMPV2-C data-see text.

caused by the strong Indian summer monsoon wind. These results generally agree with those presented by Young (1999; see his Figs. 1a,b).

Figures $2 \mathrm{a}$ and $2 \mathrm{~b}$ show months of maximum SWH and wind power for the global ocean. Peak waves (Fig. 2a) generally occur in winter months in both hemispheres and are generally nearly in phase with, or slightly lag, the months of peak winds over roughly half
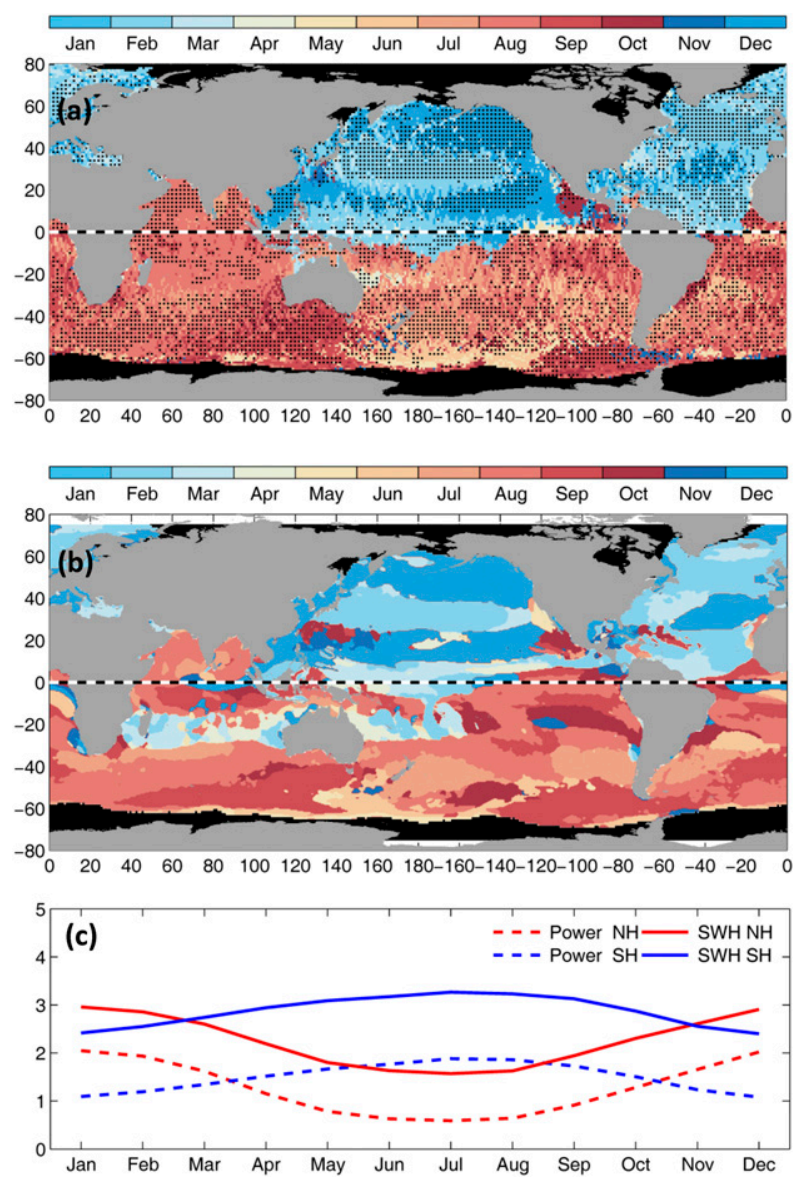

FIG. 2. (a) Calendar month of maximum SWH at each $1^{\circ} \times 1^{\circ}$ grid cell indicated by color shading. (b) As in (a), but for wind power $=\rho_{\text {air }} C_{D}$ (wind speed $)^{3}, \rho_{\text {air }}=1.23 \mathrm{~kg} \mathrm{~m}^{-3}$, and wind speed in $\mathrm{m} \mathrm{s}^{-1}$. The drag coefficient $C_{D}$ was based on Oey et al. (2006, 2007) formula, which imposes a high wind speed limit (Powell et al. 2003). (c) Area-averaged SWH (m) and wind power $\left(\mathrm{W} \mathrm{m}^{-2}\right)$ for Northern and Southern Hemispheres. In (a), stippling indicates where peak SWH and wind power occur in the same month.

of the grid points (Fig. 2b). In Fig. 2a, stippling indicates grids where peak SWH and wind power occur in the same month. They cover $48 \%$ of the global ocean points and are regions where the waves are generally "not too old"; the inverse wave age $\omega_{n}=$ (wind speed)/(phase speed) is approximately 0.65 or greater (detailed below; Fig. 3). In winter, they cover most prominently north of about $30^{\circ} \mathrm{N}$ in the North Pacific and Atlantic, in the Southern Ocean, as well as over most shelves and marginal seas: the Nordic seas, the North/Irish Sea, the Mediterranean Sea, the Arabian Sea, Bay of Bengal, along parts of the North and South American east coasts, and the East Asian seas. Smaller-scale, coastal wind features, such as the Tehuantepec $\left(\sim 16^{\circ} \mathrm{N}, 95^{\circ} \mathrm{W}\right)$ and Papagayo $\left(\sim 12^{\circ} \mathrm{N}, 86^{\circ} \mathrm{W}\right)$ jets (Chelton et al. 2000 ), 


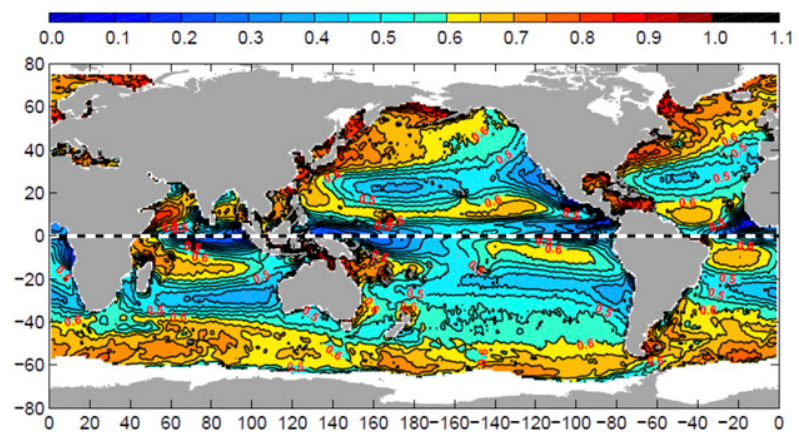

FIG. 3. The winter-mean (December, January, and February in Northern Hemisphere and June, July, and August in Southern Hemisphere), inverse wave age $\left(\omega_{n}\right)$ estimated from (1) using the observed $10-\mathrm{m}$ wind speed $V$ and significant wave height $H_{s}$ data from 1993 to 2015. Winter mean is shown because of the correspondingly strong wind and wave that dominate their trends.

and the low-level coastal jet off Peru $\left(\sim 12^{\circ} \mathrm{S}, 78^{\circ} \mathrm{W}\right)$ (Aguirre et al. 2017), which peak in the respective hemispheric winter, are also in phase with the corresponding wind seas. Because of the monthly resolution used, the correspondence with regions where $\omega_{n} \geqslant 0.65$ is only approximate. For examples: in subtropical North and South Atlantic between the $\pm 20^{\circ}$ and $\pm 40^{\circ}$ latitudes where the peak wave and wind months coincide (there are some dots in Fig. 2a) but $\omega_{n}$ is less than 0.65 , and in the Southern Ocean south of $\sim 50^{\circ} \mathrm{S}$ between $160^{\circ} \mathrm{E}$ and $120^{\circ} \mathrm{W}$ where there are no dots in Fig. 2a but $\omega_{n}>0.65$.

The remaining $52 \%$ of the ocean grids are where peaks of SWH and wind power occur in different months and waves are generally older $\left(\omega_{n} \lesssim 0.65\right)$. They are generally in the south Indian Ocean, the southeastern African coast including the Mozambique Channel, near the equator, and the eastern boundary of the ocean basin: U.S./Mexico west coast, Columbia/Peru/Chile coast, and along most of the West African coast. For examples, coastal winds off the coasts of California $\left(\sim 30^{\circ} \mathrm{N}, 120^{\circ} \mathrm{W}\right)$, Namibia $\left(\sim 30^{\circ} \mathrm{S}, 15^{\circ} \mathrm{E}\right)$, and Chile $\left(\sim 30^{\circ} \mathrm{S}, 15^{\circ} \mathrm{E}\right)$ peak in their respective hemispheric summer, and are out of phase with the peaks in SWH in winter due to the presence of strong swells (Semedo et al. 2011; Aguirre et al. 2017). A notable out-of-phase region that will be revisited later is seen in the subtropical North Pacific between $18^{\circ}$ and $28^{\circ} \mathrm{N}$; here the inverse wave age $\omega_{n}$ drops below approximately 0.5 (Fig. 3) indicating the dominance of swells. Other exceptional regions where peaks of SWH and wind power are in different months also occur east of Taiwan, southwestern Mexico, Madagascar, and northwestern Australia where strong tropical cyclones dominate and give rise to the summer-fall peak in the wind power, while on average the SWH peak is in winter.
Figure 2c shows monthly hemispheric averages of SWH and wind power. The Southern Hemispheric SWH is larger than the Northern Hemispheric SWH for all months except December, January, and February. The wind power shows no such biased asymmetry, and the Northern and Southern Hemispheric wind powers are nearly antisymmetrical with season: the Northern Hemispheric wind power is greater than the Southern Hemispheric wind power for 5 months from November to March, and the Southern Hemispheric wind power is greater than the Northern Hemispheric wind power also for 5 months, but from April to September; both hemispheric wind powers have nearly equal amplitude in October. The absence of blocking continents in the Southern Ocean allow waves to develop into greater amplitudes despite similar magnitudes of averaged wind in both hemispheres.

\section{b. Inverse wave age $\omega_{n}$}

The above-identified regions where wave is either nearly in phase with wind power or where wave and wind power bear no obvious connection correspond in general with regions dominated by either younger or older waves, respectively, that is, either wind seas or swells. To demonstrate this, Fig. 3 shows $\omega_{n}$ over the global ocean, calculated from (1) using $10-\mathrm{m}$ wind speed $V$ from the CCMPV2-C data and $H_{s}$ from the gridded satellite data. Regions with larger $\omega_{n}$ (approximately $>0.65$ ) are where the wave field is likely dominated by younger waves, mostly in the Southern Ocean and marginal seas, and on the western side of the ocean basins; they generally coincide with the aforementioned areas in Figs. $2 a$ and $2 b$ where wave is seasonally in phase with wind power. On the other hand, regions with smaller $\omega_{n}(<0.65)$ are mostly on the eastern side of the ocean basins, near the equator and in most of the Indian Ocean where, as pointed out before, seasonal wave and wind power have no obvious phase relationship.

\section{c. Wave and wind trends}

Figure 4a shows the SWH trend. Increasing SWH trend is generally seen throughout the tropical oceans, from $20^{\circ} \mathrm{S}$ to $20^{\circ} \mathrm{N}$, which include some of the world's most populated and vulnerable regions: coastal Southeast Asia, India, Bangladesh, and Myanmar, as well as the South American and African coasts including western Madagascar and the Gulf of Aden, and the coastal areas of the Gulf of Mexico, the Caribbean Sea, and the Antilles. Outside the tropics, increasing SWH trend is seen in many marginal seas in the Northern Hemisphere: the North Sea and the Baltic Sea, the Mediterranean Sea, the Persian Gulf, the East ChinaYellow Seas, the Japan Sea, and the Sea of Okhotsk, as 


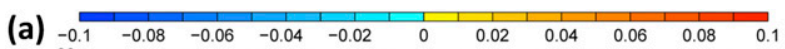

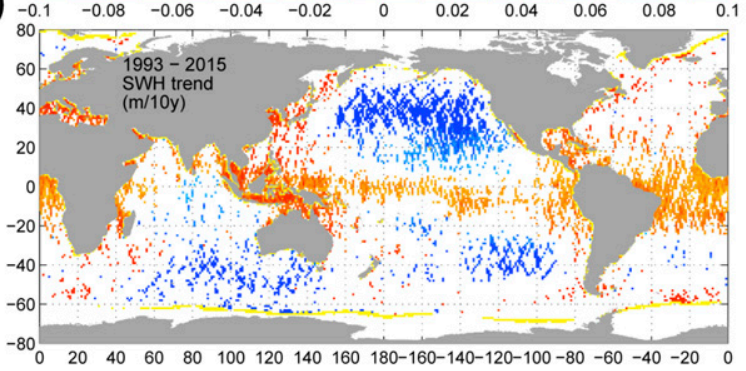

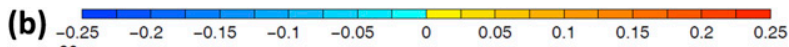

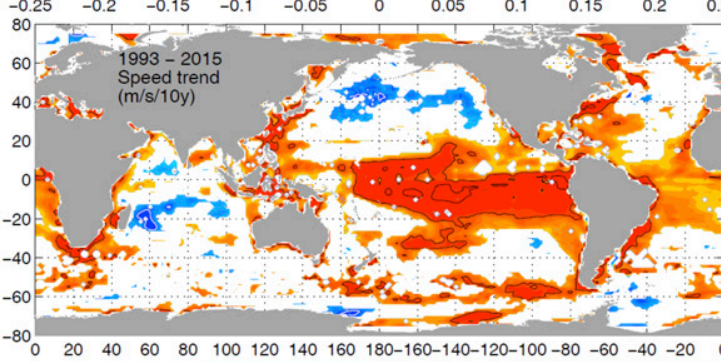

(c)

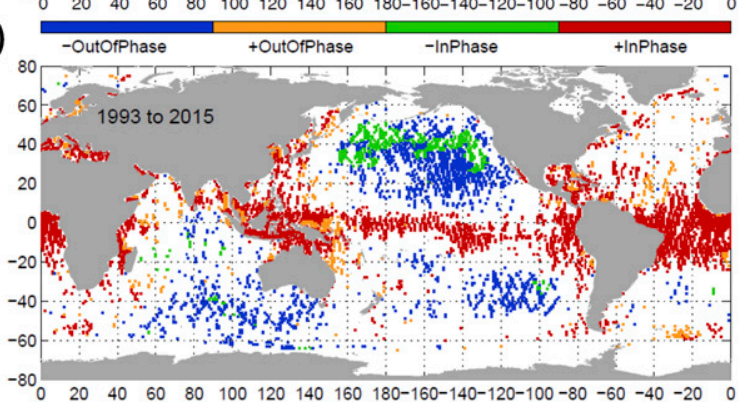

FIG. 4. Trends of (a) significant wave height SWH and (b) wind speed; legends show the units. Dots indicate where $p$ value $\leq 0.05$ (95\% confidence). (c) Red (green) indicates where both SWH and wind speed trends are positive labeled " + InPhase" (negative labeled "-InPhase"), and gold labeled "+OutOfPhase" (blue labeled "-OutOfPhase") indicates where SWH trend is positive (negative) but wind speed trend is either negative (positive) or insignificant with $p$ value $>0.05$.

well as along the North American east coast and southern Greenland. In the Southern Hemisphere, increasing SWH trend is seen around the southern African and American continents, and in the Pacific/Atlantic sectors of the Southern Ocean poleward of approximately the $60^{\circ} \mathrm{S}$ latitude. In contrast to these increasing SWH trends, which predominantly occur in the tropics and the coastal seas, decreasing SWH trends mostly occur in open oceans in the subtropical and subpolar regions, generally over three areas: the central to eastern North and South Pacific Oceans and the south Indian Ocean.

Figure $4 \mathrm{~b}$ shows the wind speed trend; the wind power trend shows similar patterns (Fig. A3b). Regions where both wind and SWH trends have the same signs generally coincide, but it is not always so. To clearly distinguish the different patterns, we use red- and green-colored grid points to indicate where the trends of SWH and wind are of the same signs: red if both trends are increasing, labeled "+InPhase," and green if both trends are decreasing, labeled "-InPhase" (Figs. 4c and A3c). On the other hand, the grids are colored gold and blue where the SWH and wind trends are of opposite signs: gold if the SWH trend is increasing and the wind trend is either decreasing or insignificant, labeled "+OutOfPhase," and blue if the SWH trend is decreasing while the wind trend is either increasing or insignificant, labeled "-OutOfPhase."

Most of the aforementioned areas of increasing SWH trend in the tropics and higher-latitude marginal seas, as well as near the southern tip of South America, where the wave is predominantly of the younger, wind-sea type, are seen to be also areas of increasing wind trend (red grids: + InPhase). In gold-colored areas in parts of the Gulf of Mexico and the Caribbean Sea, north Australian coast, and southwestern South China Sea, the wind trend is increasing but is statistically insignificant.

Decreasing SWH trend is seen in the Indo-Pacific and subtropical South Pacific sectors of the Southern Ocean, where, however, the wind speed trend is predominantly increasing (blue-colored grids). The increasing wind trend is consistent with the increasing trend of the southern annular mode since $\sim 1990$ (Fig. A4a) (Marshall 2003; Swart et al. 2015; Dätwyler et al. 2018). The opposite trends of SWH and wind speed suggest then that waves in this region may not be wholly driven directly by the local wind. Figure 3 indicates that the waves there are of mixed type consisting of some slow-moving waves or young wind seas with $\omega_{n} \geq 0.65$, and faster-moving swells $\omega_{n} \lesssim 0.65$.

Decreasing SWH is found also in subtropical central to eastern North Pacific Ocean: $160^{\circ} \mathrm{E}-120^{\circ} \mathrm{W}, 18^{\circ}-50^{\circ} \mathrm{N}$. The waves here are also of the mixed type. In the middle "green zone" (Fig. 4c, green-colored grids, roughly north of $\sim 30^{\circ} \mathrm{N}$ ), the decreasing SWH trend coincides with decreasing wind trend due to anomalous easterly over the North Pacific (west of $\sim 120^{\circ} \mathrm{W}$ ) associated with the "cool" pattern of the Pacific decadal oscillation since the late 1990s (Fig. A4b) (e.g., Newman et al. 2016). However, at many locations surrounding the "green zone," in particular those to its south and east, the decreasing wind trend is insignificant (Fig. 4c blue-colored grids; roughly $18^{\circ}-40^{\circ} \mathrm{N}$ and east of the date line).

\section{d. Trends of relative sea level and wave setup near the coast}

Approximately $10 \%$ of the world's population, around 600 million, lives within coastal zones less than $10 \mathrm{~m}$ above the local sea level (McGranahan et al. 2007). Longterm (secular) trend of local water level modulated by 

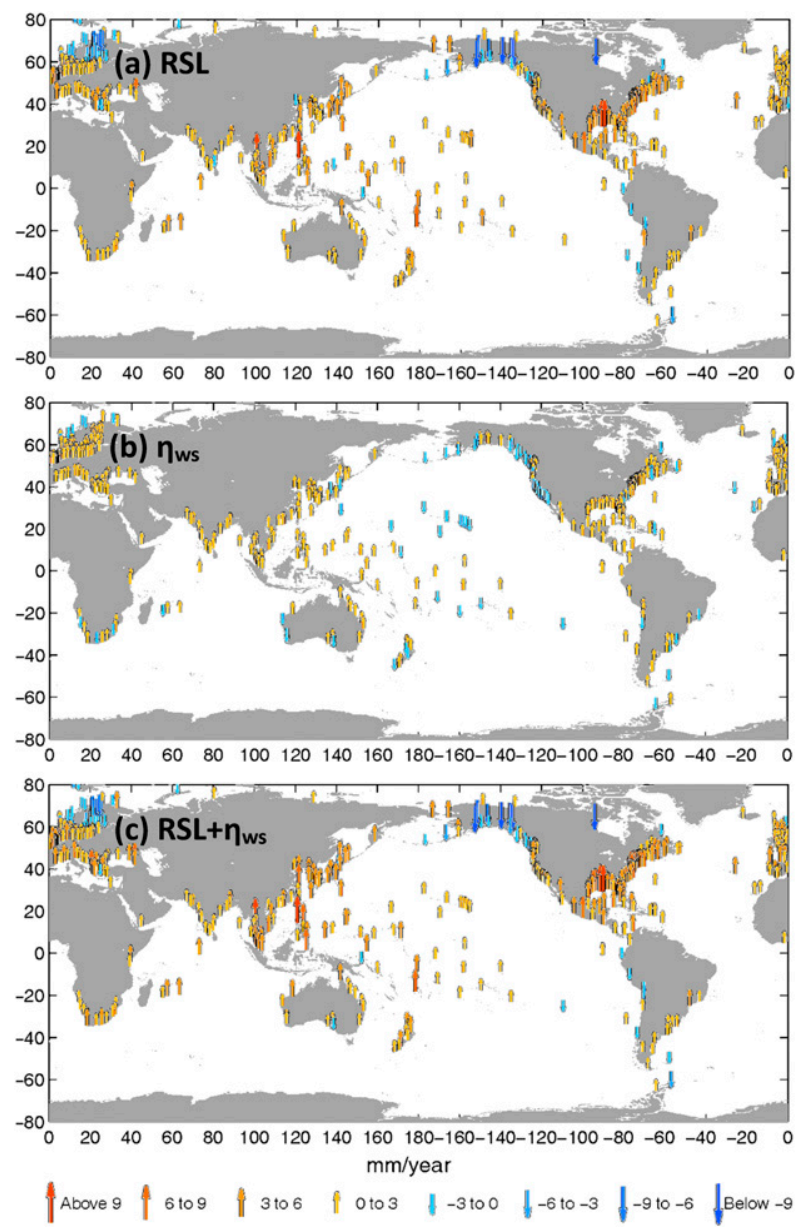

FIG. 5. Secular trends of (a) RSL at tide gauge stations around the globe with data length 50 years and longer, and (b) 23-yr, 1993 2015 trends of wave setup " $\eta_{\mathrm{ws}}$ " and (c) RSL $+\eta_{\mathrm{ws}}$. See Fig. A6 for plots of coastal seas of Europe, Mediterranean, eastern United States, and East Asia where strong increasing trends are seen.

regional trends of storm surge and surface wave intensity is therefore of immense practical and societal importance and relevant. Trend of storm surge depends on intensity and movement of cyclones and is the topic of many studies (see Oey and Chou 2016 for a summary). Here we focus on effects of waves.

Warming climate has caused global absolute sea level $\left(\eta_{\mathrm{ASL}}\right)$ to steadily rise in the past several decades, due to seawater expansion and addition of ocean water mass by land-ice and glacier melting (Fig. A5) (Domingues et al. 2008; Leuliette and Willis 2011). Locally, however, the relevant water level is the relative sea level $\left(\eta_{\mathrm{RSL}}\right)$ referenced to the local solid surface of Earth, and therefore depends on the vertical movement of the Earth crust, $d h_{\mathrm{EC}} / d t$ (positive upward) (see section 2, data and method). For $d h_{\mathrm{EC}} / d t$, the most recent significant Earth crust movement began following the deglaciation after

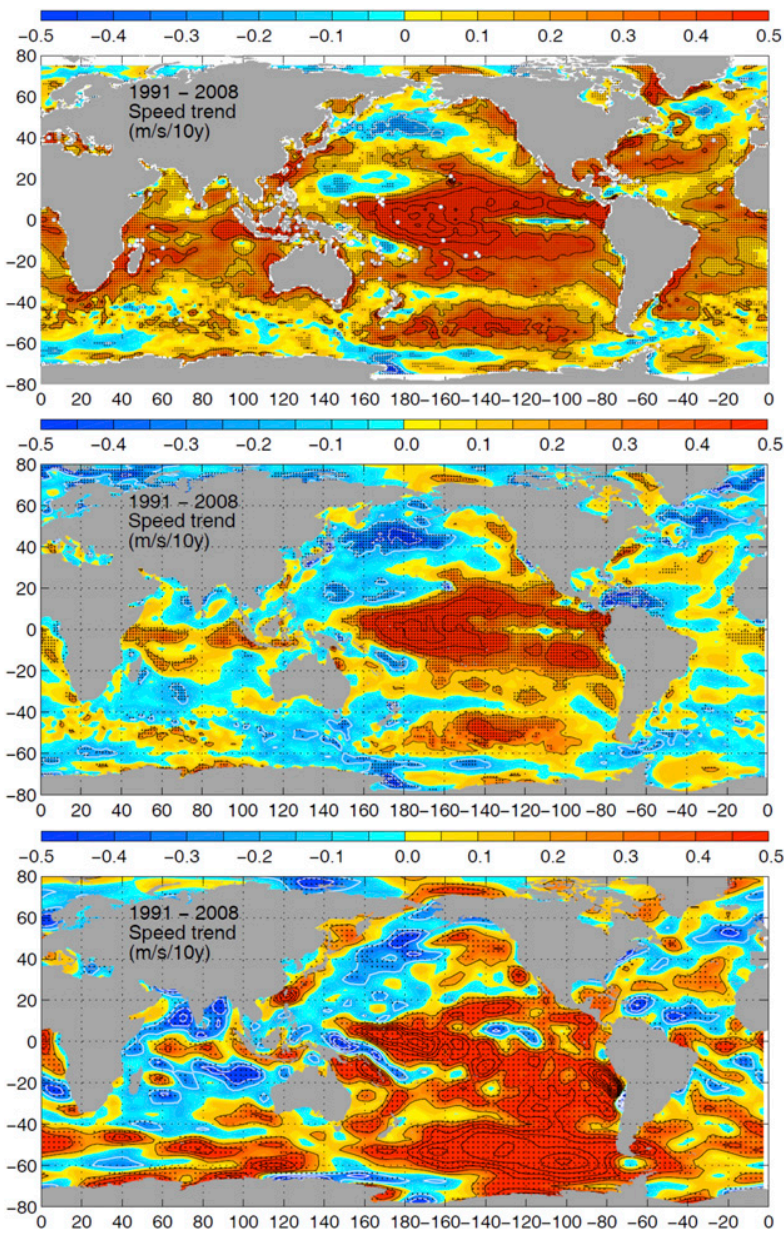

FIG. A1. Comparison of wind speed trends from 1991 to 2008, the same period as in Young et al's (2011) wind speed trend (their Fig. 1 top), using: (top) CCMPV2-C (this study), (middle) ECMWF, and (bottom) NCEP.

the last glacial maximum some 21000 years ago, and it continues today, albeit at an exponentially slower rate. During this glacial isostatic adjustment (Mitrovica and Peltier 1993), the solid Earth rebounds (i.e., uplifts, $\left.d h_{\mathrm{EC}} d t>0\right)$ in the "near field" where ice sheets and glaciers once existed including much of northern Europe, Eurasia, and North America, it collapses (i.e., sinks, $\left.d h_{\mathrm{EC}} / d t<0\right)$ in the peripheral regions, and it has a more complicated, second-order response in the "far field" (Milne and Mitrovica 1998; Milne and Shennan 2013). Prominent uplift occurs in northern Europe (Simon et al. 2018, their Fig. 1) including the Gulf of Bothnia in northern Baltic Sea (Ekman 1996; Milne et al. 2001) and Norway (Romundset et al. 2010; Simpson et al. 2015). Uplift also occurs in northeastern Canada: the Hudson and James Bays (Mitrovica and Peltier 1995; Tsuji et al. 2009), and in southern Alaska and the northwestern United States and Canada (Hicks 
$\begin{array}{lllllllllllll}0.0 & 0.1 & 0.2 & 0.3 & 0.4 & 0.5 & 0.6 & 0.7 & 0.8 & 0.9 & 1.0 & 1.1\end{array}$
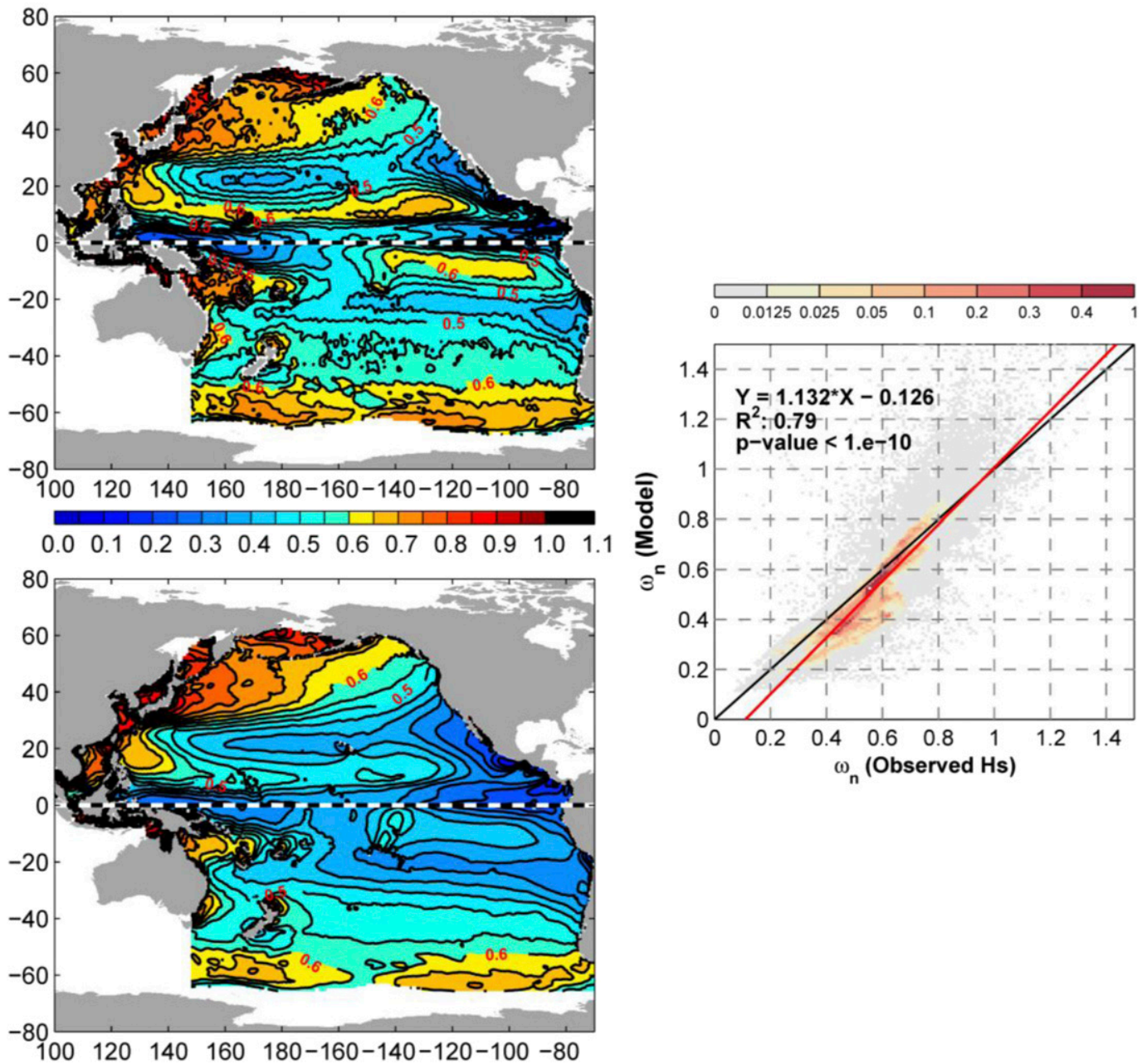

FIG. A2. Comparison of estimated, observed inverse wave age $\left(\omega_{n}\right)$ from (1) (top left) with the $\omega_{n}$ directly calculated from the Lin et al. (2019) WAVEWATCH III model output (bottom left) for the Pacific Ocean, averaged from 1993 to 2015 for hemispheric winter months DJF (JJA) Northern (Southern) Hemisphere. (right) Regression of model vs observed $\omega_{n}$. Color indicates data density per $0.02 \times 0.02 \omega_{n}$-bin, scale normalized by a maximum density of 210. Red line is the regression line and the corresponding equation, the $r^{2}$ and $p$ value are shown in the top-left legend. For reference, the $45^{\circ}$ ("perfect") line is shown as the black line. The regression line (including $r^{2}$ and $p$ value) is nearly entirely determined by the high-data-density points, density $>0.1$ (the redcolored area), rather than the low-density points (faint red and gray colored areas). Where the red-colored area meets the "perfect" black line, near $\omega_{n} \approx 0.6-0.7$, the observed $\omega_{n}$ estimated from the wave-growth function agrees with the direct modeled $\omega_{n}$, and $\omega_{n}=0.6-0.7$ is taken as the approximate transition value above (below) which the observed sea state is considered to consist of mostly younger (older) waves.

and Shofnos 1965; Larsen et al. 2004; Yousefi et al. 2018; Clark et al. 2019). We use tide gauge data to calculate the secular trends of relative sea level, $d \eta_{\mathrm{RSL}} / d t$ [see (2)], at coastal stations around the globe (Fig. 5a).

Despite the global absolute sea level rise $d \eta_{\mathrm{ASL}} / d t>0$ due to warming, Fig. 5a shows strong falling relative sea levels at the above-mentioned sites of significant postglacial rebound where trends are dominated by land uplift: northern Europe, northeastern Canada, and northwestern
America. There is also falling RSL trend along the Pacific side of the South American continent, which is, however, related to uplift caused by active seismic activity (Marquardt et al. 2004; Bookhagen et al. 2006; Melnick et al. 2009; Isla and Angulo 2016; Rodríguez Tribaldos et al. 2017). At other stations, rising trends are seen, contributed by both rising absolute sea level due to global warming and, at some sites, by sinking land in the peripheral of deglaciation area, for example, in the 


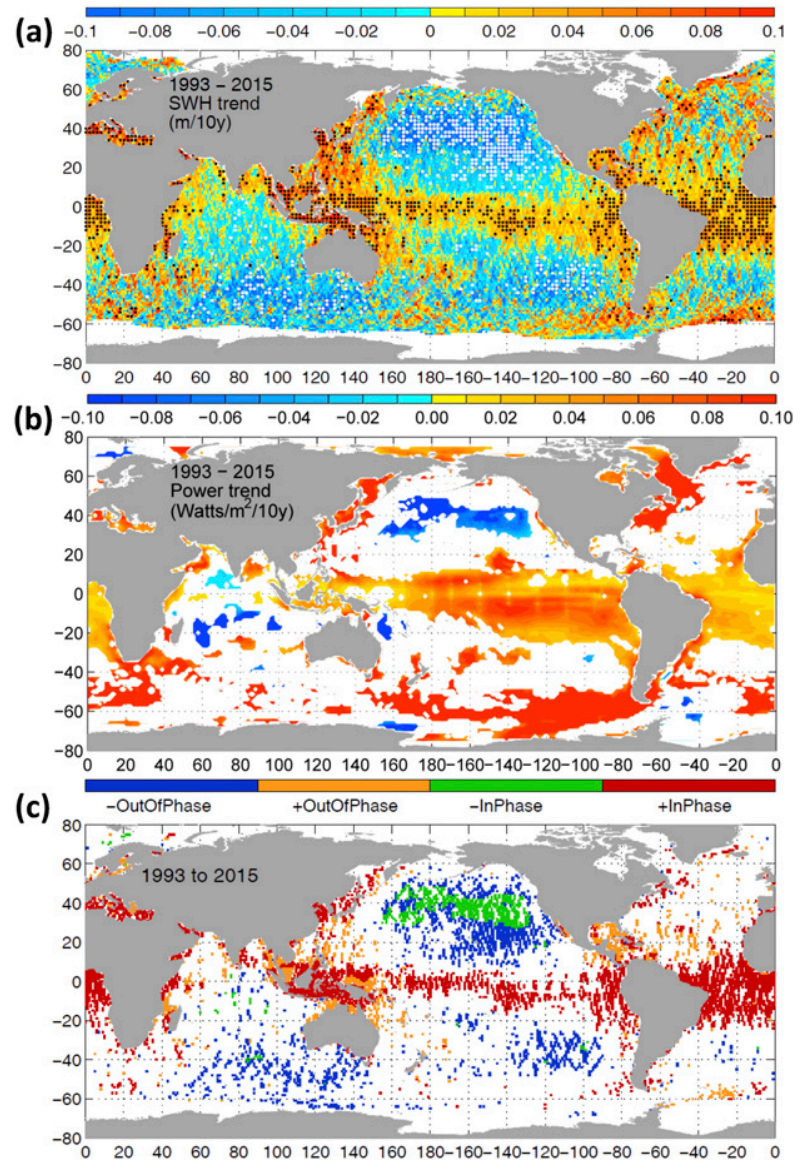

FIG. A3. Trends of (a) significant wave height SWH and (b) wind power; legends show the units. (a) Same as Fig. 4a, but that all grid points are color-filled and dots show significant points (95\% confidence); only significant points are shown in (b). (c) Red (green) indicates where both SWH and wind power trends are positive labeled "+InPhase" (negative labeled "-InPhase"), and gold labeled "+OutOfPhase" (blue labeled "-OutOfPhase") indicates where SWH trend is positive (negative) but wind power trend is either negative (positive) or insignificant with $p$ value $>0.05$.

mid-Atlantic states of the eastern United States (Maryland, Virginia, and North Carolina) (Peltier and Tushingham 1991; Davis and Mitrovica 1996; Engelhart et al. 2009; Piecuch et al. 2018), as well as by local land subsidence due to, for example, groundwater usage (e.g., New Orleans, Bangkok; Milliman and Haq 1996; Nutalaya et al. 1996).

We estimate how local, secular RSL trends (Fig. 5a) may be modulated by trends of wave setup $\left(\eta_{\mathrm{ws}}\right)$ forced by the regional open-ocean wave climate in recent decades since 1993. The $\eta_{\mathrm{ws}}$ is calculated using (3) (see section 2, data and method), and its trends are shown in Fig. $5 \mathrm{~b}$ at the tide gauge stations, many of which are located in sheltered bays and/or inlets where wave effects are weak. The $\eta_{\mathrm{ws}}$ is therefore interpreted as wave setup over the nearby coastline along which the
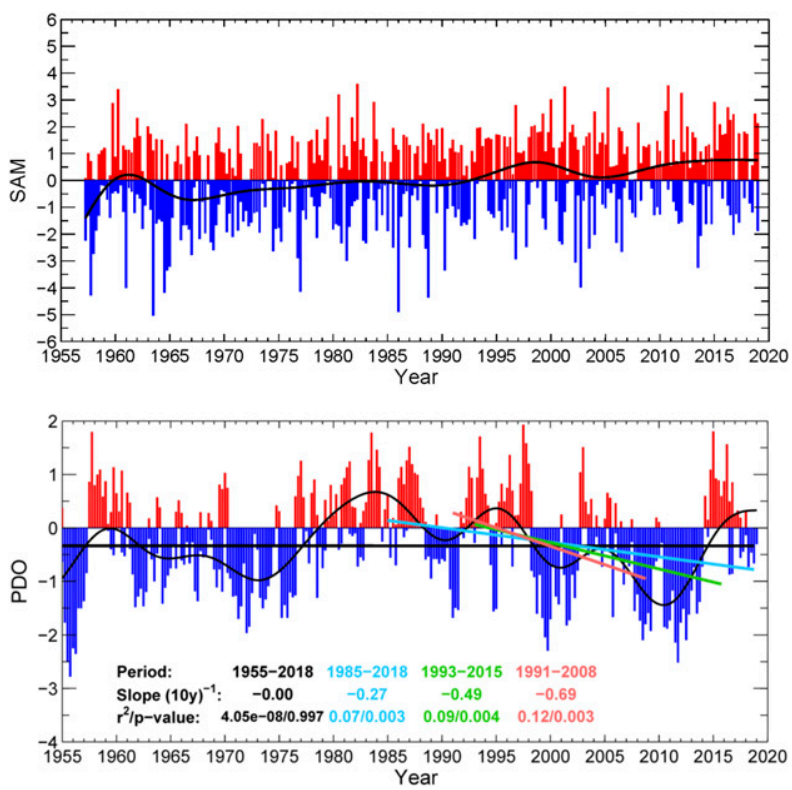

FIG. A4. (top) SAM index from Marshall (2003) (https://legacy. bas.ac.uk/met/gjma/sam.html), and (bottom) Pacific decadal oscillation (PDO) index (https://www.ncdc.noaa.gov/teleconnections/pdo/). Bars are monthly values. Thick line is 60 -month running mean, showing increasing (decreasing) SAM (PDO) since $\sim$ mid-1980s. PDO trend lines are shown for different periods, slopes, $r^{2}$, and $p$ values indicated in legends; in particular, the 3 periods: $1985-2018$ [aqua, Young and Ribal (2019)], 1993-2015 (green, this study), and 1991-2008 [pink, Young et al. (2011), wind speed trend] show increasingly more negative or "cooler" PDO phase. The wholeperiod trend, 1955-2018 (black), is included for reference, showing zero trend.

corresponding secular RSL trend may be estimated using the tide gauge measurement. Increasing $\eta_{\mathrm{ws}}$ trends (Fig. 5b) mimic closely the $H_{s}$ trends, but weaker, since $\eta_{\mathrm{ws}} \sim H_{s} / V^{1 / 5}$ and the wind speed (or wind power) trends are also generally increasing at the same coastal stations (Fig. A6). Nonetheless, the $\eta_{\text {ws }}$ trends (Fig. 5b) are increasing at many of the stations where the RSL trends are also increasing, for example, the North and Irish Seas, the Mediterranean Sea, the East Asian seas, India, and eastern United States. The rising relative sea level trends are therefore amplified by increasing wave setup trends along these populated coasts, potentially making them more vulnerable to floods (Fig. 5c; see Fig. A7 for enlarged plots in the above-mentioned regions). In contrast, decreasing $\eta_{\mathrm{ws}}$ trends are seen at stations in the central Pacific and along the U.S. West Coast.

\section{Summary and discussion}

This study calculates trends of sea surface wave, wind and coastal wave setup in the global ocean, from 1993 to 2015, and provides explanations of their interconnection 


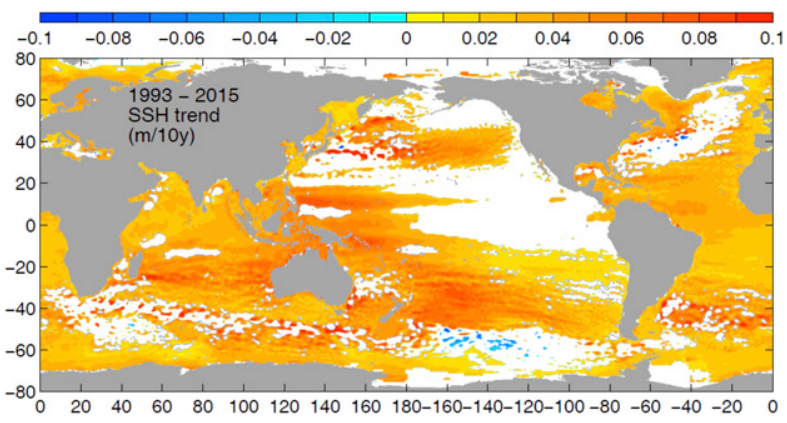

FIG. A5. Absolute sea level trend from 1993 to 2015 based on satellite altimetry. Color indicates trend significant at the $95 \%$ confidence level; the scale is $\pm 0.1 \mathrm{~m}(10 \mathrm{yr})^{-1}\left(= \pm 10 \mathrm{~mm} \mathrm{yr}^{-1}\right)$. Data are https://www.aviso.altimetry.fr/en/data.html; see supporting information in Sun et al. (2017) and Oey et al. (2018) for details of the data processing. The global average of $3.4 \pm 0.3 \mathrm{~mm} \mathrm{yr}^{-1}$ is consistent with the value of about $3.3 \pm 0.3 \mathrm{~mm} \mathrm{yr}^{-1}$ reported in the literature (Bindoff et al. 2007; Hay et al. 2015).

with the aid of a wave model and some semiempirical relationships. In general, increasing wave and wind trends occur in regions dominated by younger waves, while decreasing wave trends unrelated (or statistically insignificantly related) to wind are found where older waves dominate. Increasing wave setup trends are found along many populated coastlines, including regions where the local infrastructure and economy are potentially more vulnerable to extreme events.

A complex, mixed pattern of wind-wave relationship is found over the central to eastern North Pacific. Here, the coexistence where SWH and wind trends appear to be related (Fig. 4c, green) and where they do not (Fig. 4c, blue) is interesting. Measurements in the Baltic Sea (Smedman et al. 1999, their Fig. 7) and during the San Clemente Ocean Probing Experiment (offshore of San Diego, California) (Grachev and Fairall 2001, their Fig. 3) indicate that the surface vertical momentum flux undergoes a rapid decrease as the wave state changes from young wind seas to older swells, near an empirical $\omega_{n}$-transition range of approximately $0.8 \geqslant \omega_{n} \gtrsim 0.5$. Using direct numerical simulation based on the NavierStokes equations, Sullivan et al. (2000, their Table 1 and Fig. 10b) showed that the rapid decrease in the surface vertical momentum flux is caused by a change of sign near $\omega_{n} \approx 1$, in the model, of the form stress or pressure drag due to waves. The form drag changes from being positive for young wind seas, which acts in concert with turbulent (and viscous) stresses to decelerate the wind, to negative for older swells, which causes a reversed, upward transfer of momentum from wave to wind, and therefore acts to reduce the total surface drag, or even to accelerate the wind in the direction of the swells (Harris 1966). Thus, "swell waves perform work on the
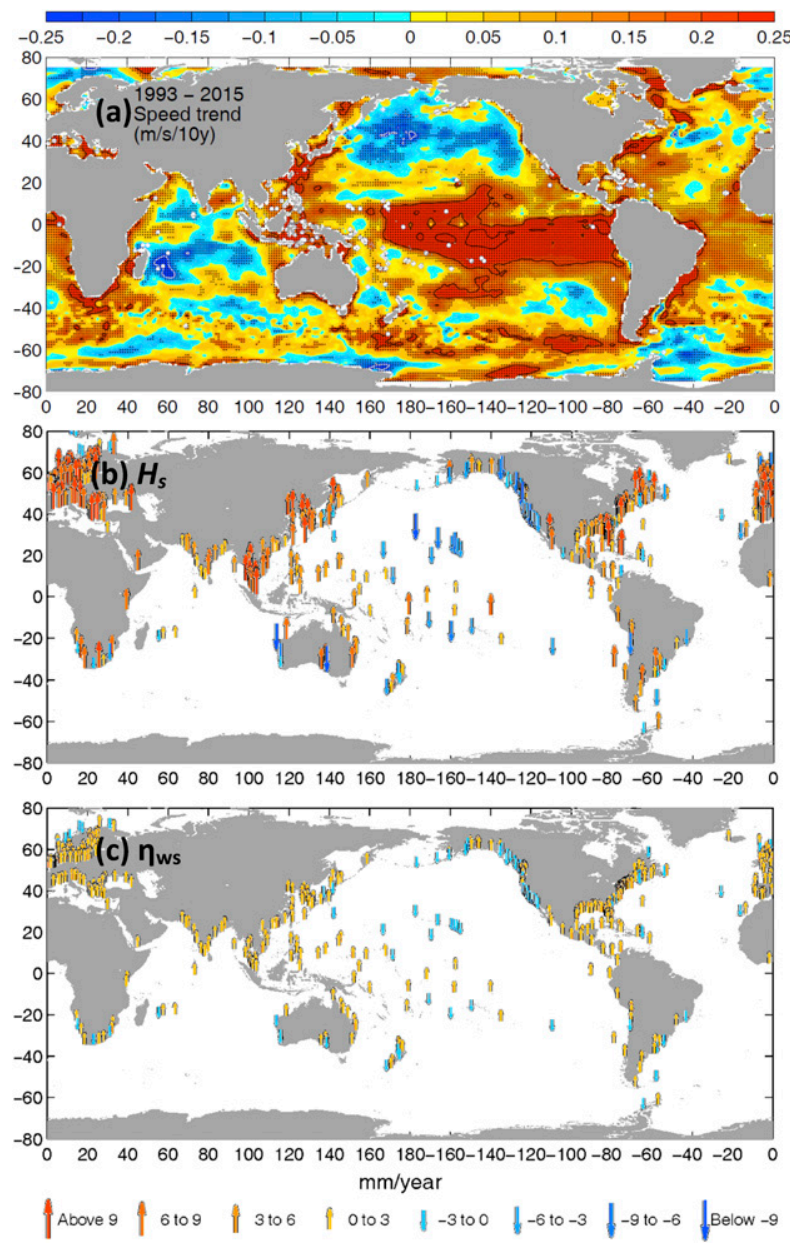

FIG. A6. Trends (1993-2015) of (a) wind speed $V$ (dots indicate significance at $95 \%$ confidence level), and of (b) SWH $H_{s}$ and (c) wave setup $\eta_{\mathrm{ws}}$ at tide gauge stations. The $H_{s}$ trends are strongly increasing at many stations where $V$ s are also increasing (e.g., North and Irish Seas, Mediterranean Sea, East Asian seas, India, and eastern United States). However, since $\eta_{\mathrm{ws}} \sim H_{s} / V^{1 / 5}$, the increasing $\eta_{\mathrm{ws}}$ trends are more moderate.

overlying atmosphere because they propagate faster than the wind, producing a forward thrust on the flow" (Semedo et al. 2009). During winter in the aforementioned central to eastern North Pacific region, swells propagate southeastward, produced by powerful storms that traverse west to east across the region (Fig. A8). The $\omega_{n}$ decreases eastward and southward from a windsea state with $\omega_{n} \geqslant 0.65$ north and west of the region, to a swell state with $\omega_{n}$ dropping below 0.5 south and east (Fig. 3). We posit that this $\omega_{n}$-transition (i.e., $\omega_{n}$ changing from approximately 0.65 to 0.5 and smaller) is where the form drag decreases rapidly or even reverses sign. Thus, while the total surface drag retards the wind north and west and wind energy is transferred to the wave, it decreases rapidly south and east because of 

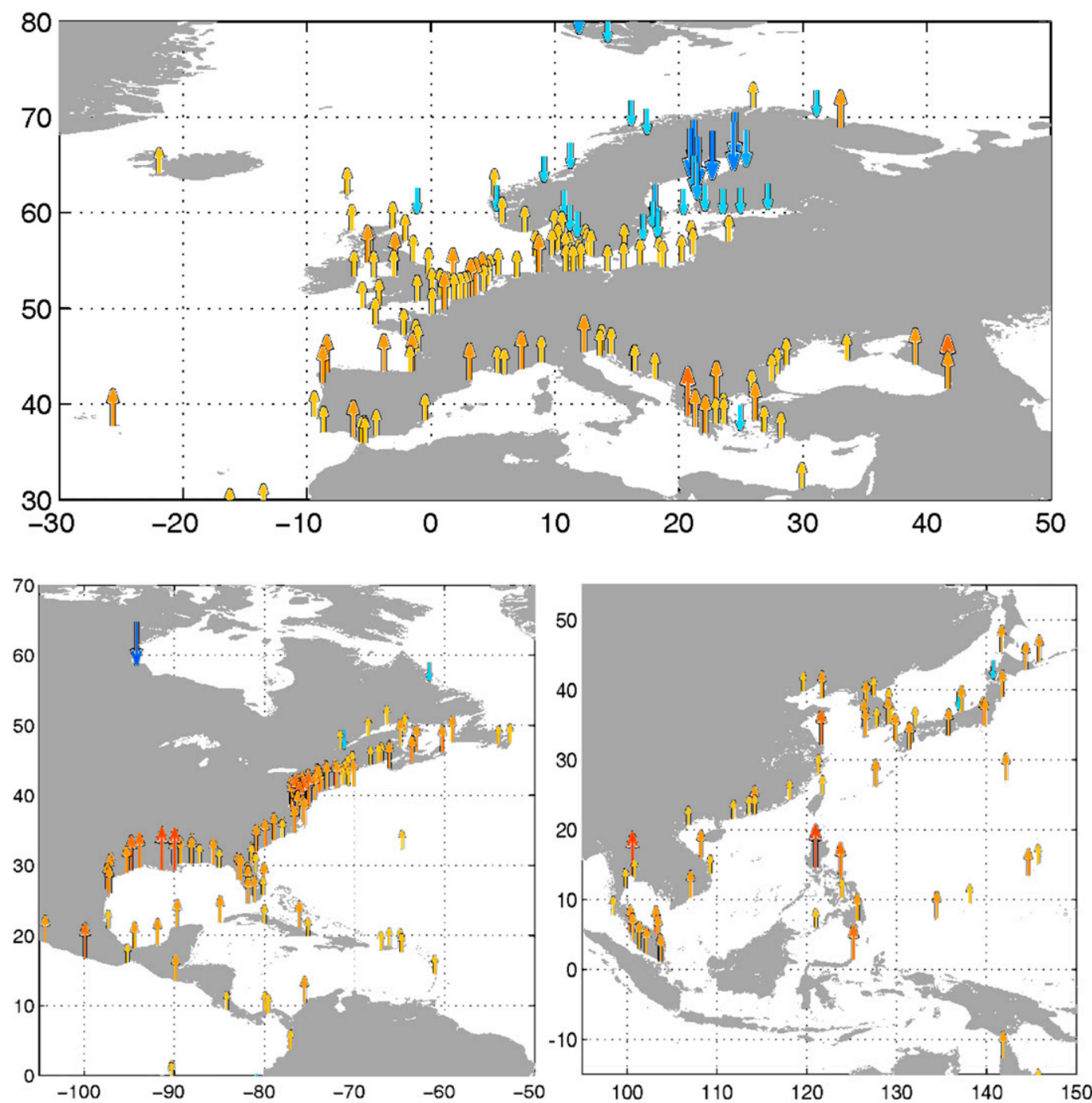

\section{$\mathrm{mm} /$ year}

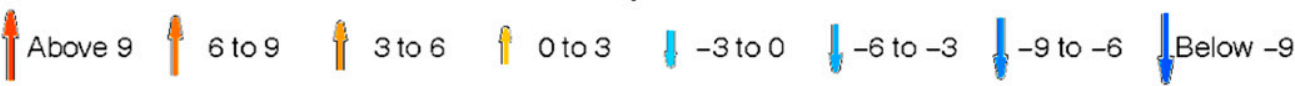

FIG. A7. Enlarged trend plots of RSL $+\eta_{\mathrm{ws}}$ (from Fig. 5) for coastal seas of Europe, Mediterranean, eastern United States, and East Asia where strong increasing trends of local relative sea level and wave setup are seen.

reduced or reversed form drag as the wind flows over the swell-dominated region; there, the wind experiences a nearly frictionless surface or is even driven by the swell field. This would result in SWH and wind speed being more significantly correlated (e.g., both have decreasing trends, Fig. 4c, green) in the north and west, while they become less significantly correlated (Fig. 4c, blue) in the south and east. In other words, younger waves contribute to further decelerate the wind in the "green zone," tending to make the decreasing wind trend significant, while wind is decoupled from (or driven by) the swell field at the blue points, and wind trend can be insignificant or increasing even as wave trend is decreasing (Fig. 4c, blue). The central North Pacific appears to be a fertile region for this $\omega_{n}$ transition. A similar $\omega_{n}$-transition region also occurs in the south Indian Ocean $\left(15^{\circ}-50^{\circ} \mathrm{S}\right)$. More focused observational and modeling studies may be carried out to further explore the phenomenon.

The 23-yr analysis period used in our study is relatively short, which means that the calculated trends are multidecadal "snapshots" rather than being truly long term. As mentioned previously, the wind speed trend is consistent with the negative trend of the Pacific decadal oscillation and positive trend of the southern annular 


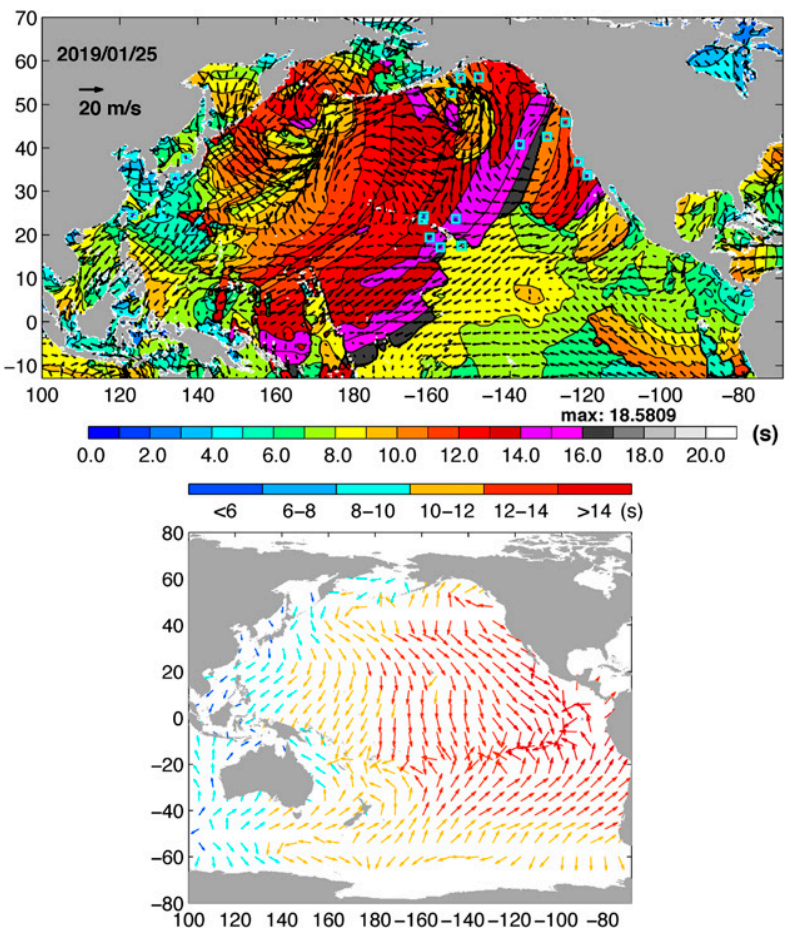

FIG. A8. Lin et al. (2019) WAVEWATCH III model. (top) Wave period ( $s$; color with contours) and wind vectors during the passage of a cyclone west to east across the North Pacific on 25 Jan 2019; squares indicate buoy locations where model validations were conducted by Lin et al. (bottom) Peak wave vector with length representing peak wave period averaged for boreal winter from December through February, and from 1993 to 2015 .

mode since the 1990s. Should these climate modes reverse, the global patterns of wind, wave and wave setup trends may be expected to also reverse, that is, the "warm-cool" colors of Figs. 4 and 5b would reverse, as it is unlikely that the global pattern of the wave age would fundamentally change. Such interdecadal reversal of the trend pattern at the global scale is practically important; it will be interesting to further investigate the phenomenon using longer (a few hundred or more years) data, say, from models.

Finally, we examine our results in comparison to those obtained by Young et al. (2011), Ruggiero (2013), and Young and Ribal (2019). The relative shortness of the time periods used in these trend calculations (including ours) explain most of the differences. The influence on wind and wave of El Niño-Southern Oscillation and other interannual/interdecadal climate signals is significant, particularly in the Pacific Ocean (Lin et al. 2019). The PDO index rises rapidly from its lowest negative value (since the 1950s) in $\sim 2010$ to a slightly positive value in $\sim 2018$ (Fig. A4), so that trend calculations with data that end in $\sim 2010$ (Young et al. 2011; Ruggiero 2013), 2015 (this study), and 2018 (Young and Ribal 2019) can yield wind and wave trends that are different especially in the Pacific Ocean. For example, at buoys along the U.S. Pacific Northwest coast, Ruggiero (2013) found a rising wave setup trend, caused by rising wind and hence SWH trends along the Pacific Northwest coast due to the strong negative PDO pattern for the period that ends in $\sim 2010$; the PDO slope is -0.69 $(10 \mathrm{yr})^{-1}$ from 1991 to 2008 (Fig. A4). By contrast, we obtained a decreasing SHW trend (Fig. A3a) and hence also a wave setup trend (Fig. $5 \mathrm{c}$ ) at stations along the U.S. West Coast for the period that ends in 2015 when the PDO slope is weaker $=-0.49(10 \mathrm{yr})^{-1}$ from 1993 to 2015. For the Young and Ribal (2019) period from 1985 to 2018, the PDO slope weakens further to -0.27 $(10 \mathrm{yr})^{-1}$, resulting in weakly positive wind speed trend in the central North Pacific (see their Fig. 1A), compared to the significant negative trend we obtained (Fig. 4b). In the tropical Indo-Pacific, the wind speed trend displays an El Niño-like pattern of significantly negative trend over the western equatorial Pacific including the Maritime Continent (see their Fig. 1A), compared to the positive trend we obtained (Fig. 4b). It is interesting that over the central to eastern North Pacific, including the U.S. northwest coast, Young and Ribal (2019) obtained a significantly negative SWH trend (their Fig. 2A), which agrees well with our negative SHW trend (Fig. 4a). These negative SWH trends are consistent with the negative wind trend that we obtain (Fig. 4b), which we explained above in terms of how wind seas and swells can affect the surface form drag but are inconsistent with the slightly positive wind speed trend that Young and Ribal (2019) obtained. Further investigation is required.

Acknowledgments. We thank the three reviewers for their comments and are grateful to the reviewer who alerted us of the paper by Young and Ribal (2019). Links to data used here are as follows: NDBC: https://www.ndbc. noaa.gov/; SSH: https://www.aviso.altimetry.fr/en/data/ products/sea-surface-height-products.html; SWH: ftp://ftp. ifremer.fr/ifremer/cersat/products/swath/altimeters/waves/; tide gauge: https://tidesandcurrents.noaa.gov/sltrends/ sltrends.html and https://www.psmsl.org/; and wind:

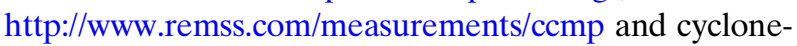
corrected: http://140.115.23.77:5000/sharing/NORublUfU. This research was in part supported by Taiwan MOST Grants 107-2611-M-008-003 and 107-2111-M-008-035. Author contributions: LO designed the study, interpreted the results and wrote the paper, with contributions from YCL. YCL analyzed the data. Both authors discussed the results. 


\section{APPENDIX}

\section{Supporting Figures}

Figures A1-A8 and captions provide further details of the analyses and results presented in the text.

\section{REFERENCES}

Aguirre, C., J. A. Rutllant, and M. Falvey, 2017: Wind waves climatology of the southeast Pacific Ocean. Int. J. Climatol., 37, 4288-4301, https://doi.org/10.1002/joc.5084.

Allan, J., and P. Komar, 2000: Are ocean wave heights increasing in the eastern North Pacific? Eos, Trans. Amer. Geophys. Union, 81, 561-567, https://doi.org/10.1029/EO081I047P00561-01.

Andreas, E, and K. A. Emanuel, 2001: Effects of sea spray on tropical cyclone intensity. J. Atmos. Sci., 58, 3741-3751, https://doi.org/ 10.1175/1520-0469(2001)058<3741:EOSSOT>2.0.CO;2.

Ardhuin, F., B. Chapron, and F. Collard, 2009: Observation of swell dissipation across oceans. Geophys. Res. Lett., 36, L06607, https://doi.org/10.1029/2008GL037030.

Atlas, R., R. N. Hoffman, J. Ardizzone, S. M. Leidner, and J. C. Jusem, 2009: Development of a new cross-calibrated, multiplatform (CCMP) ocean surface wind product. 13th Conf. on Integrated Observing and Assimilation Systems for Atmosphere, Oceans, and Land Surface, Phoenix, AZ, Amer. Meteor. Soc., 14B.1, https://ams.confex.com/ams/pdfpapers/145957.pdf.

Aucan J., R. K. Hoeke, C. D. Storalzz, J. Stopa, M. Wandres, and R. Lowe, 2019: Waves do not contribute to global sea-level rise. Nat. Climate Change, 9, 2-3, https://doi.org/10.1038/ S41558-018-0377-5.

Bendat, J. S., and A. G. Piersol, 1986: Random Data. Wiley, 566 pp.

Bindoff, N. L., and Coauthors, 2007: Observations: Oceanic climate change and sea level. Climate Change 2007: The Physical Science Basis, S. Solomon et al., Eds., Cambridge University Press, 385-432.

Bookhagen, B., H. P. Echtler, D. Melnick, M. R. Strecker, and J. Q. G. Spencer, 2006: Using uplifted Holocene beach berms for paleoseismic analysis on the Santa María Island, south-central Chile. Geophys. Res. Lett., 33, L15302, https://doi.org/10.1029/2006GL026734.

Chelton, D. B., M. H. Freilich, and S. K. Esbensen, 2000: Satellite observations of the wind jets off the Pacific Coast of Central America. Part I: Case studies and statistical characteristics. Mon. Wea. Rev., 128, 1993-2018, https://doi.org/10.1175/15200493(2000)128<1993:SOOTWJ >2.0.CO;2.

—, M. G. Schlax, M. H. Freilich, and R. F. Milliff, 2004: Satellite measurements reveal persistent small-scale features in ocean winds. Science, 303, 978-983, https://doi.org/10.1126/science.1091901.

Clark, J. A., P. E. Haidle, and L. N. Cunningham, 2002: Comparison of satellite altimetry to tide gauge measurement of sea level: Predictions of glacio-isostatic adjustment. J. Climate, 15, 3291-3300, https:// doi.org/10.1175/1520-0442(2002)015<3291:COSATT>2.0.CO;2.

_ J. X. Mitrovica, and K. Latychev, 2019: Glacial isostatic adjustment in central Cascadia: Insights from three-dimensional Earth modeling. Geology, 47, 295-298, https://doi.org/10.1130/G45566.1.

Cox, A. T., and V. R. Swail, 2001: A global wave hindcast over the period 1958-1997: Validation and climate assessment. J. Geophys. Res., 106, 2313-2329, https://doi.org/10.1029/ 2001JC000301.
Dätwyler, C., R. Neukom, N. J. Abram, A. J. E. Gallant, M. Grosjean, M. Jacques-Coper, D. J. Karoly, and R. Villalba, 2018: Teleconnection stationarity, variability and trends of the southern annular mode (SAM) during the last millennium. Climate Dyn., 51, 2321-2339, https://doi.org/10.1007/s00382017-4015-0.

Davis, J. L., and J. X. Mitrovica, 1996: Glacial isostatic adjustment and the anomalous tide gauge record of eastern North America. Nature, 379, 331-333, https://doi.org/10.1038/ $379331 \mathrm{a} 0$.

Domingues, C., J. Church, N. White, P. Gleckler, S. Wijffels, P. Barker, and J. Dunn, 2008: Improved estimates of upperocean warming and multi-decadal sea-level rise. Nature, $\mathbf{4 5 3}$, 1090-1093, https://doi.org/10.1038/NATURE07080.

Domingues, R., G. Goni, M. Baringer, and D. L. Volkov, 2018: What caused the accelerated sea level changes along the United States East Coast during 2010-2015? Geophys. Res. Lett., 45, 13367 13 376, https://doi.org/10.1029/2018GL081183.

Donelan, M. A., M. Curcic, S. S. Chen, and A. K. Magnusson, 2012: Modeling waves and wind stress. J. Geophys. Res., 117, C00J23, https://doi.org/10.1029/2011JC007787.

Douglas, B. C., and W. R. Peltier, 2002: The puzzle of global sea-level rise. Phys. Today, 55, 35-40, https://doi.org/10.1063/1.1472392.

Ekman, M., 1996: A consistent map of the postglacial uplift of Fennoscandia. Terra Nova, 8, 158-165, https://doi.org/10.1111/ j.1365-3121.1996.tb00739.x.

Engelhart, S. E., B. P. Horton, B. C. Douglas, W. R. Peltier, and T. E. Törnqvist, 2009: Spatial variability of late Holocene and 20th century sea-level rise along the Atlantic coast of the United States. Geology, 37, 1115-1118, https://doi.org/10.1130/G30360A.1.

Fan, Y., S.-J. Lin, I. M. Held, A. Yu, and H. L. Tolman, 2012: Globa ocean surface wave simulation using a coupled atmospherewave model. J. Climate, 25, 6233-6252, https://doi.org/10.1175/ JCLI-D-11-00621.1.

Farrell, W. E., and B. C. Clark, 1976: On postglacial sea level Geophys. J. Int., 46, 647-667, https://doi.org/10.1111/j.1365246X.1976.tb01252.x.

Grachev, A. A., and C. W. Fairall, 2001: Upward momentum transfer in the marine boundary layer. J. Phys. Oceanogr., 31 1698-1711, https://doi.org/10.1175/1520-0485(2001)031<1698: $\mathrm{UMTITM}>2.0 . \mathrm{CO} ; 2$.

Goddard, P. B., J. Yin, S. M. Griffies, and S. Zhang, 2015: An extreme event of sea-level rise along the northeast coast of North America in 2009-2010. Nat. Commun., 6, 6346, https://doi.org/ $10.1038 /$ ncomms 7346.

Gulev, S. K., and L. Hasse, 1999: Changes of wind waves in the North Atlantic over the last 30 years. Int. J. Climatol., 19, 1091-1117, https://doi.org/10.1002/(SICI)1097-0088(199908) 19:10<1091::AID-JOC403>3.0.CO;2-U.

Harris, D. L., 1966: The wave-driven wind. J. Atmos. Sci., 23, 688-693, https://doi.org/10.1175/1520-0469(1966)023<0688 TWDW $>2.0 . \mathrm{CO} ; 2$.

Hay, C. C., E. Morrow, R. E. Kopp, and J. X. Mitrovica, 2015: Probabilistic reanalysis of 20th-century sea-level rise. Nature, 517, 481-488, https://doi.org/10.1038/nature14093.

Hicks, S. D., and W. Shofnos, 1965: The determination of land emergence from sea-level observations in southeast Alaska. J. Geophys. Res., 70, 3315-3320, https://doi.org/10.1029/JZ070i014p03315.

Huang, S.-M., and L.-Y. Oey, 2019a: Land-falling typhoons are controlled by the meridional oscillation of the Kuroshio Extension. Climate Dyn., 52, 2855-2867, https://doi.org/10.1007/s00382-018-4295-z.

- and — 2019b: Malay Archipelago forest loss to cash crops and urban contributes to weaken the Asian summer monsoon. 
J. Climate, 32, 3189-3205, https://doi.org/10.1175/JCLI-D-180467.1.

Hwang, P. A., and M. A. Sletten, 2008: Energy dissipation of windgenerated waves and whitecap coverage.J. Geophys. Res., 113, C02012, https://doi.org/10.1029/2007JC004277.

_ , and E. J. Walsh, 2016: Azimuthal and radial variation of windgenerated surface waves inside tropical cyclones. J. Phys. Oceanogr., 46, 2605-2621, https://doi.org/10.1175/JPO-D-16-0051.1.

Hyndman, D., and D. Hyndman, 2010: Natural Hazards and Disasters. 3rd ed. Brooks-Cole Learning, 609 pp.

Isla, F. I., and R. J. Angulo, 2016: Tectonic processes along the South America coastline derived from quaternary marine terraces. J. Coastal Res., 32, 840-852, https://doi.org/10.2112/ JCOASTRES-D-14-00178.1.

Komen, G. J., L. Cavaleri, M. Donelan, K. Hasselmann, S. Hasselmann, and P. A. E. M. Janssen, 1994: Dynamics and Modelling of Ocean Waves. Cambridge University Press, 532 pp.

Kushnir, Y., V. J. Cardon, J. G. Greenwood, and M. A. Cane, 1997: The recent increase in North Atlantic wave heights. J. Climate, 10, 2107-2113, https://doi.org/10.1175/1520-0442(1997)010<2107: TRIINA $>2.0 . \mathrm{CO} ; 2$.

Larsen, C. F., R. J. Motyka, J. T. Freymueller, K. A. Echelmeyer, and E. R. Ivins, 2004: Geophys. J. Int., 158, 1118-1133, https:// doi.org/10.1111/j.1365-246X.2004.02356.x.

Leuliette, E. W., and J. K. Willis, 2011: Balancing the sea level budget. Oceanography, 24, 122-129, https://doi.org/10.5670/ oceanog.2011.32.

Li, G., S.-P. Xie, C. He, and Z. Chen, 2017: Western Pacific emergent constraint lowers projected increase in Indian summer monsoon rainfall. Nat. Climate Change, 7, 708-714, https://doi.org/10.1038/nclimate3387.

Lin, Y.-C., L.-Y. Oey, and A. Orfila, 2019: Two 'faces' of ENSOinduced surface waves during the tropical cyclone season. Prog. Oceanogr., 175, 40-54, https://doi.org/10.1016/j.pocean. 2019.03.004.

Longuet-Higgins, M. S., 1952: On the statistical distribution of the heights of sea waves. J. Mar. Res., 11, 245-266.

_ physical discussion, with applications. Deep-Sea Res., 11, 529562, https://doi.org/10.1016/0011-7471(64)90001-4.

Lueck, R., and R. Reid, 1984: On the production and dissipation of mechanical energy in the ocean. J. Geophys. Res., 89, 3439 3445, https://doi.org/10.1029/JC089iC03p03439.

Marquardt, C., A. Lavenu, L. Ortlieb, E. Godoy, and D. Comte, 2004: Coastal neotectonic in southern central Andes: Uplift and deformation of marine terraces in northern Chile $\left(27^{\circ} \mathrm{S}\right)$. Techtonophysics, 394, 193-219, https://doi.org/10.1016/j.tecto. 2004.07.059.

Marshall, G. J., 2003: Trends in the southern annular mode from observations and reanalyses. J. Climate, 16, 4134-4143, https:// doi.org/10.1175/1520-0442(2003)016<4134:TITSAM >2.0.CO;2.

Massom, R. A., T. A. Scambos, L. G. Bennetts, P. Reid, V. A. Squire, and S. E. Stammerjohn, 2018: Antarctic ice shelf disintegration triggered by sea ice loss and ocean swell. Nature, 558, 383-389, https://doi.org/10.1038/s41586-018-0212-1.

McGranahan, G., D. Balk, and B. Anderson, 2007: The rising tide: Assessing the risks of climate change and human settlements in low elevation coastal zones. Environ. Urban., 19, 17-37, https://doi.org/10.1177/0956247807076960.

Melet, A., B. Meyssignac, R. Almar, and G. Le Cozannet, 2018: Under-estimated wave contribution to coastal sea-level rise. Nat. Climate Change, 8, 234-239, https://doi.org/10.1038/ s41558-018-0088-y.
——— - _ - 2019: Reply to 'Waves do not contribute to global sea-level rise.' Nat. Climate Change, 9, 2-3, https:// doi.org/10.1038/s41558-018-0378-4.

Mellor, G. L., and A. Blumberg, 2004: Wave breaking and ocean surface thermal response. J. Phys. Oceanogr., 34, 693-698, https://doi.org/10.1175/2517.1.

—, M. A. Donelan, and L.-Y. Oey, 2008: A surface wave model for coupling with numerical ocean circulation models. $J$. Atmos. Oceanic Technol., 25, 1785-1807, https://doi.org/10.1175/ 2008JTECHO573.1.

Melnick, D., B. Bookhagen, M. R. Strecker, and H. P. Echtler, 2009: Segmentation of megathrust rupture zones from fore-arc deformation patterns over hundreds to millions of years, Arauco peninsula, Chile. J. Geophys. Res., 114, B01407, https://doi.org/ 10.1029/2008JB005788.

Merrifield, M. A., and M. E. Maltrud, 2011: Regional sea level trends due to a Pacific trade wind intensification. Geophys. Res. Lett., 38, L21605, https://doi.org/10.1029/2011GL049576.

Milliman, J. D., and B. U. Haq, Eds., 1996: Sea-Level Rise and Coastal Subsidence. Springer, 375 pp.

Milne, G. A., and J. X. Mitrovica, 1998: Postglacial sea-level change on a rotating Earth. Geophys. J. Int., 133, 1-19, https://doi.org/ 10.1046/j.1365-246X.1998.1331455.x.

— change. Encyclopedia of Quaternary Science, Elsevier, 452459, https://doi.org/10.1016/b978-0-444-53643-3.00135-7.

_ J. L. Davis, J. X. Mitrovica, H.-G. Scherneck, J. M. Johansson, M. Vermeer, and H. Koivula, 2001: Space-geodetic constraints on glacial isostatic adjustments in Fennoscandia. Science, 291, 2381-2385, https://doi.org/10.1126/science.1057022.

Mitrovica, J. X., and W. R. Peltier, 1993: Present-day secular variations in the zonal harmonics of the Earth's geopotential. J. Geophys. Res., 98, 4509-4526, https://doi.org/10.1029/92JB02700.

— and - 1995: Constraints on mantle viscosity based upon the inversion of post-glacial uplift data from the Hudson Bay region. Geophys. J. Int., 122, 353-377, https://doi.org/10.1111/ j.1365-246X.1995.tb07002.x.

_- M. Tamisiea, J. L. Davis, and G. A. Milne, 2001: Polar ice mass variations and the geometry of global sea level change. Nature, 409, 1026-1029, https://doi.org/10.1038/35059054.

Möller, D., 2010: Chemistry of the Climate System. De Gruyter Publishing, $722 \mathrm{pp}$.

Mound, J. E., and J. X. Mitrovica, 1998: True polar wander as a mechanism for second-order sea-level variations. Science, 279, 534-537, https://doi.org/10.1126/science.279.5350.534.

Mulkern, A., 2017: Rising sea levels will hit California harder than other places. Sci. Amer., 27, E\&E News, 27 April, https:// www.scientificamerican.com/article/rising-sea-levels-will-hitcalifornia-harder-than-other-places/.

Nakamura, N., T. Sampe, Y. Tanimoto, and A. Shimpo, 2004: Observed associations among storm tracks, jet streams and midlatitude oceanic fronts. Earth's Climate: The Ocean-Atmosphere Interaction, Geophys. Monogr., Vol. 147, Amer. Geophys. Union, 329-345, https://doi.org/10.1029/147GM18.

Nerem, R. S., and G. T. Mitchum, 2001: Sea level change. Satellite Altimetry and Earth Sciences: A Handbook of Techniques and Applications, L.-L. Fu and A. Cazenave, Eds., Academic Press, 329-347.

Newman, M., and Coauthors, 2016: The Pacific decadal oscillation, revisited. J. Climate, 29, 4399-4427, https://doi.org/10.1175/ JCLI-D-15-0508.1.

Nutalaya, O., R. N. Yong, T. Chumnankit, and S. Buapeng, 1996: Land subsidence in Bangkok during 1978-1988. Sea-Level Rise 
and Coastal Subsidence, J. D. Milliman and B. U. Haq, Eds., Springer, $375 \mathrm{pp}$.

Oey, L.-Y., and S. Chou, 2016: Evidence of rising and poleward shift of storm surge in western North Pacific in recent decades. J. Geophys. Res. Oceans, 121, 5181-5192, https://doi.org/ 10.1002/2016JC011777.

—, T. Ezer, D.-P. Wang, S.-J. Fan, and X.-Q. Yin, 2006: Loop current warming by Hurricane Wilma. Geophys. Res. Lett., 33, L08613, https://doi.org/10.1029/2006GL025873.

,,,--- X.-Q. Yin, and S.-J. Fan, 2007: Hurricane-induced motions and interaction with ocean currents. Cont. Shelf Res., 27, 1249-1263, https://doi.org/10.1016/j.csr.2007.01.008.

—, M.-C. Chang, Y.-L. Chang, Y.-C. Lin, and F.-H. Xu, 2013: Decadal warming of coastal China seas and coupling with winter monsoon and currents. Geophys. Res. Lett., 40, 62886292, https://doi.org/10.1002/2013GL058202.

—, Y.-L. Chang, Y.-C. Lin, M.-C. Chang, S. Varlamov, and Y. Miyazawa, 2014: Cross flows in the Taiwan Strait in winter. J. Phys. Oceanogr., 44, 801-817, https://doi.org/10.1175/JPOD-13-0128.1.

—, M.-C. Chang, S.-M. Huang, Y.-C. Lin, and M.-A. Lee, 2015: The influence of shelf-sea fronts on winter monsoon over East China Sea. Climate Dyn., 45, 2047-2068, https://doi.org/10.1007/ s00382-014-2455-3.

_ J. Wang, and M.-A. Lee, 2018: Fish catch is related to the fluctuations of a western boundary current. J. Phys. Oceanogr., 48, 705-721, https://doi.org/10.1175/JPO-D-17-0041.1.

Peltier, W. R., 2004: Global glacial isostasy and the surface of the ice-age earth: The ICE-5G (VM2) model and GRACE. Annu. Rev. Earth Planet. Sci., 32, 111-149, https://doi.org/10.1146/ annurev.earth.32.082503.144359.

_ , and A. M. Tushingham, 1991: Influence of glacial isostatic adjustment on tide gauge measurements of secular sea level change. J. Geophys. Res., 96, 6779-6796, https://doi.org/10.1029/ 90JB02067.

Piecuch, C. G., P. Huybers, C. C. Hay, A. C. Kemp, C. M. Little, J. X. Mitrovica, R. M. Ponte, and M. P. Tingley, 2018: Origin of spatial variation in US East Coast sea-level trends during 1900-2017. Nature, 564, 400-408, https://doi.org/10.1038/s41586018-0787-6.

Powell, M. D., P. J. Vickery, and T. A. Reinhold, 2003: Reduced drag for high wind speeds in TCs. Nature, 422, 279-283, https:// doi.org/10.1038/nature01481.

Press, W. H., S. A. Teukolsky, W. T. Vetterling, and B. P. Flannery, 1992: Numerical Recipes. Cambridge Univ Press, 933 pp.

Rodríguez Tribaldos, V., N. J. White, G. G. Roberts, and M. J. Hoggard, 2017: Spatial and temporal uplift history of South America from calibrated drainage analysis. Geochem. Geophys. Geosyst., 18, 2321-2353, https://doi.org/10.1002/2017GC006909.

Rogers, J. S., S. G. Monismith, D. Koweek, W. Torres, and R. B. Dunbar, 2016: Thermodynamics and hydrodynamics in an atoll reef system and their influence on coral cover. Limnol. Oceanogr., 61, 2191-2206, https://doi.org/10.1002/lno.10365.

Romundset, A., S. L. Øystein, J. Mangerud, and J. I. Svendsen, 2010: The first Holocene relative sea-level curve from the middle part of Hardangerfjorden, western Norway. Boreas, 39, 87-104, https://doi.org/10.1111/j.1502-3885.2009.00108.x.

Ruggiero, P., 2013: Is the intensifying wave climate of the U.S. Pacific Northwest increasing flooding and erosion risk faster than sealevel rise? J. Waterw. Port Coastal Ocean Eng., 139, 88-97, https://doi.org/10.1061/(ASCE)WW.1943-5460.0000172.

Salamon, P., N. Casagli, H. Cloke, and K. Horsburgh, 2017: Understanding disaster risk: Hazard related risk issues-Section
II: Hydrological risk. Science for Disaster Risk Management 2017: Knowing Better and Losing Less, K. Poljanšek et al., Eds., Publications Office of the European Union, 192-239, https://doi.org/10.2788/688605.

Semedo, A., Ø. Saetra, A. Rutgersson, K. Kahma, and H. Pettersson, 2009: Wave-induced wind in the marine boundary layer. J. Atmos. Sci., 66, 2256-2271, https://doi.org/10.1175/ 2009JAS3018.1.

_ the wind sea and swell climate and variability from ERA-40. J. Climate, 24, 1461-1479, https://doi.org/10.1175/2010JCLI3718.1.

Sen, P. K., 1968: Estimates of the regression coefficient based on Kendall's tau. J. Amer. Stat. Assoc., 63, 1379-1389, https:// doi.org/10.1080/01621459.1968.10480934.

Serafin, K. A., P. Ruggiero, and H. F. Stockdon, 2017: The relative contribution of waves, tides, and nontidal residuals to extreme total water levels on U.S. West Coast sandy beaches. Geophys. Res. Lett., 44, 1839-1847, https://doi.org/10.1002/2016gl071020.

Simon, K. M., R. E. M. Riva, M. Kleinherenbrink, and T. Frederikse, 2018: The glacial isostatic adjustment signal at present day in northern Europe and the British Isles estimated from geodetic observations and geophysical models. Solid Earth, 9, 777-795, https://doi.org/10.5194/se-9-777-2018.

Simpson, M. J. R., Coauthors, 2015: Sea level change for Norway: Past and present observations and projections to 2100. Norwegian Centre for Climate Services Rep. 1/2015, 156 pp., https://www.miljodirektoratet.no/globalassets/publikasjoner/ M405/M405.pdf

Smedman, A., U. Högström, H. Bergström, A. Rutgersson, K. K. Kahma, and H. Pettersson, 1999: A case study of air-sea interaction during swell conditions. J. Geophys. Res., 104, 25 833-25 851, https://doi.org/10.1029/1999JC900213.

Stockdon, H. F., R. A. Holman, P. A. Howd, and A. H. Sallenger, 2006: Empirical parameterization of setup, swash, and runup. Coastal Eng., 53, 573-588, https://doi.org/10.1016/j.coastaleng. 2005.12.005

Sullivan, P. P., J. C. McWilliams, and C.-H. Moeng, 2000: Simulation of turbulent flow over idealized water waves. J. Fluid Mech., 404, 47-85, https://doi.org/10.1017/S0022112099006965.

Sun, J., L. Oey, F. H. Xu, and Y.-C. Lin, 2017: Sea level rise, surface warming, and the weakened buffering ability of South China Sea to strong typhoons in recent decades. Nat. Sci. Rep., 7 , 7418, https://www.nature.com/articles/s41598-017-07572-3.

Swapna, P., J. Jyoti, R. Krishnan, N. Sandeep, and S. M. Griffies, 2017: Multidecadal weakening of Indian summer monsoon circulation induces an increasing northern Indian Ocean sea level. Geophys. Res. Lett., 44, 10 560-10 572, https://doi.org/ 10.1002/2017GL074706.

Swart, N. C., J. C. Fyfe, N. Gillett, and G. J. Marshall, 2015: Comparing trends in the southern annular mode and surface westerly jet. J. Climate, 28, 8840-8859, https://doi.org/10.1175/ JCLI-D-15-0334.1.

Tamisiea, M. E., J. X. Mitrovica, G. A. Milne, and J. L. Davis, 2001: Global geoid and sea level changes due to present-day ice mass fluctuations. J. Geophys. Res., 106, 30 849-30 863, https:// doi.org/10.1029/2000JB000011.

Theil, H., 1950a: A rank-invariant method of linear and polynomial regression analysis. I. Proc. Ned. Akad. Wet., 53, 386-392.

_ 1950b: A rank-invariant method of linear and polynomial regression analysis. II. Proc. Ned. Akad. Wet., 53, 521-525.

— 1950c: A rank-invariant method of linear and polynomial regression analysis. III. Proc. Ned. Akad. Wet., 53, 13971412. 
Trenberth, K. E., and Coauthors, 2007: Observations: Surface and atmospheric climate change. Climate Change 2007: The Physical Science Basis, S. Solomon et al., Eds., Cambridge University Press, 235-336.

Tsuji, L. J. S., N. Gomez, J. X. Mitrovica, and R. Kendall, 2009: Post-glacial isostatic adjustment and global warming in subarctic Canada: Implications for islands of the James Bay region. Arctic, 62, 458-467, https://doi.org/10.14430/arctic176.

Volkov, D. L., S.-K. Lee, R. Domingues, H. Zhang, and M. Goes, 2019: Interannual sea level variability along the southeastern seaboard of the United States in relation to the gyre-scale heat divergence in the North Atlantic. Geophys. Res. Lett., 46, 7481-7490, https://doi.org/10.1029/2019GL083596.

Vousdoukas, M. I., L. Mentaschi, E. Voukouvalas, M. Verlaan, and L. Feyen, 2017: Extreme sea levels on the rise along Europe's coasts. Earth's Future, 5, 304-323, https://doi.org/10.1002/ 2016EF000505.

,,,---- S. Jevrejeva, L. P. Jackson, and L. Feyen, 2018: Global probabilistic projections of extreme sea levels show intensification of coastal flood hazard. Nat. Commun., 9, 2360, https://doi.org/10.1038/s41467-018-04692-w.

Wallace, J. M., T. P. Mitchell, and C. Deser, 1989: The influence of SST on surface wind in the eastern equatorial Pacific: Seasonal and interannual variability. J. Climate, $\mathbf{2}$, 1492-1499, https://doi.org/10.1175/1520-0442(1989)002<1492: TIOSST $>2.0 . \mathrm{CO} ; 2$.

Wentz, F. J., J. Scott, R. Hoffman, M. Leidner, R. Atlas, and J. Ardizzone, 2016: Cross-calibrated multi-platform ocean surface wind vector analysis product V2, 1987-ongoing. National Center for Atmospheric Research Computational and Information Systems Laboratory Research Data Archive, accessed 9 January 2017, http://rda.ucar.edu/datasets/ds745.1/.

Wunsch, C., and R. Ferrari, 2004: Vertical mixing, energy, and the general circulation of the oceans. Annu. Rev. Fluid Mech., 36, 281-314, https://doi.org/10.1146/annurev.fluid.36.050802.122121.

Young, I. R., 1999: Seasonal variability of the global ocean wind and wave climate. Int. J. Climatol., 19, 931, https://doi.org/10.1002/ (SICI)1097-0088(199907)19:9<931::AID-JOC412>3.0.CO;2-O. , and A. Ribal, 2019: Multiplatform evaluation of global trends in wind speed and wave height. Science, 364, 548-552, https:// doi.org/10.1126/science.aav9527.

, S. Zieger, and A. V. Babanin, 2011: Global trends in wind speed and wave height. Science, 332, 451-455, https://doi.org/ 10.1126/science.1197219.

Yousefi, M., G. A. Milne, R. Love, and L. Tarasov, 2018: Glacial isostatic adjustment along the Pacific coast of central North America. Quat. Sci. Rev., 193, 288-311, https://doi.org/10.1016/ j.quascirev.2018.06.017.

Zhang, L., and L. Oey, 2019a: Young ocean waves favor the rapid intensification of tropical cyclones-A global observational analysis. Mon. Wea. Rev., 147, 311-328, https://doi.org/10.1175/ MWR-D-18-0214.1.

- and - 2019b: An observational analysis of ocean surface waves in tropical cyclones in the western North Pacific Ocean. J. Geophys. Res. Oceans, 124, 184-195, https://doi.org/10.1029/ $2018 \mathrm{JC} 014517$. 